\title{
Hydropower Capital and O\&M Costs: An Exploration of the FERC Form 1 Data
}

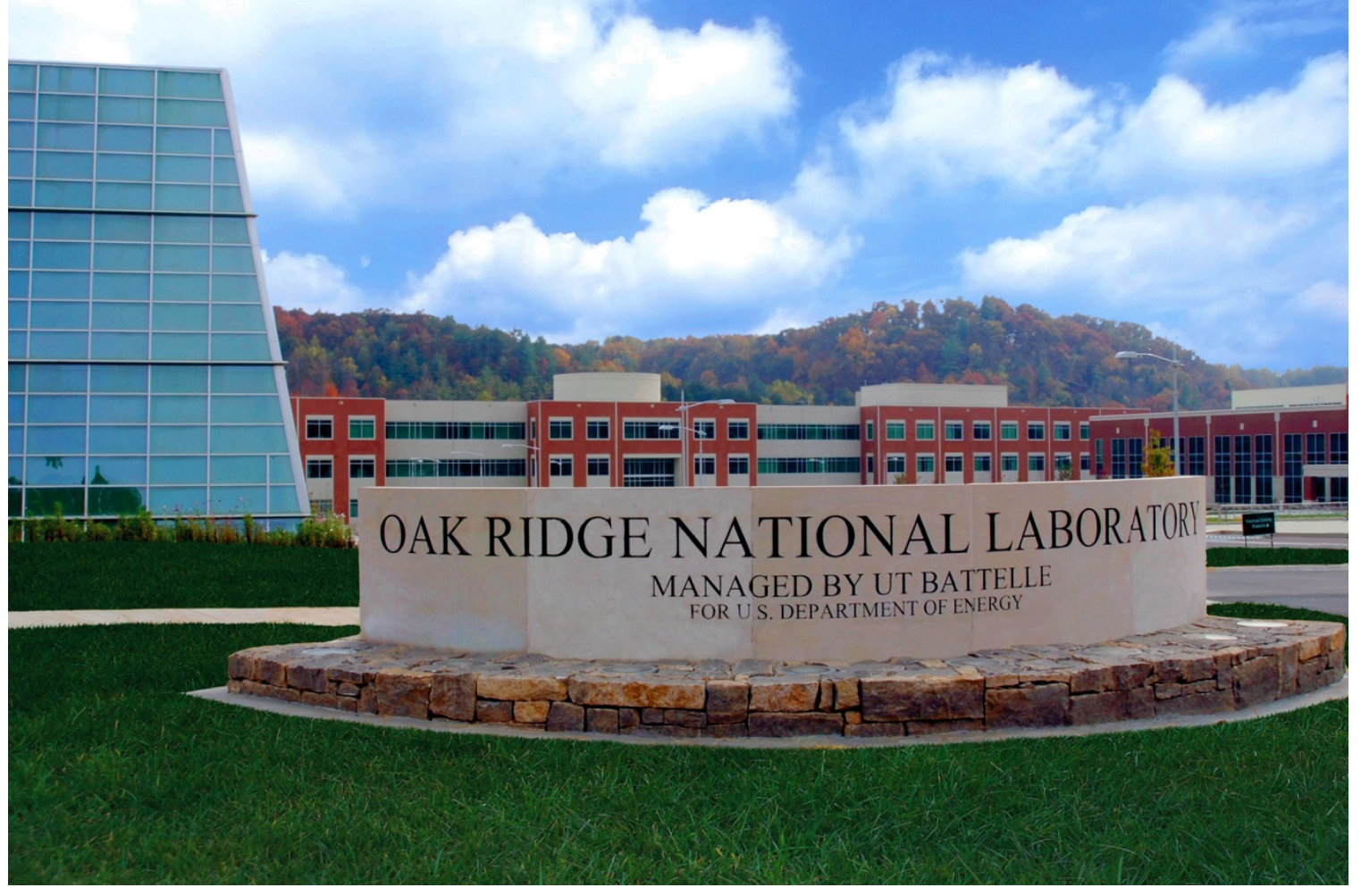

Gbadebo Oladosu

Colin Sasthav

February 2022

Approved for public release. 


\section{DOCUMENT AVAILABILITY}

Reports produced after January 1, 1996, are generally available free via OSTI.GOV.

Website www.osti.gov

Reports produced before January 1, 1996, may be purchased by members of the public from the following source:

National Technical Information Service

5285 Port Royal Road

Springfield, VA 22161

Telephone 703-605-6000 (1-800-553-6847)

TDD 703-487-4639

Fax 703-605-6900

E-mail info@ntis.gov

Website http://classic.ntis.gov/

Reports are available to US Department of Energy (DOE) employees, DOE contractors, Energy Technology Data Exchange representatives, and International Nuclear Information System representatives from the following source:

Office of Scientific and Technical Information

PO Box 62

Oak Ridge, TN 37831

Telephone 865-576-8401

Fax 865-576-5728

E-mail reports@osti.gov

Website https://www.osti.gov/

This report was prepared as an account of work sponsored by an agency of the United States Government. Neither the United States Government nor any agency thereof, nor any of their employees, makes any warranty, express or implied, or assumes any legal liability or responsibility for the accuracy, completeness, or usefulness of any information, apparatus, product, or process disclosed, or represents that its use would not infringe privately owned rights. Reference herein to any specific commercial product, process, or service by trade name, trademark, manufacturer, or otherwise, does not necessarily constitute or imply its endorsement, recommendation, or favoring by the United States Government or any agency thereof. The views and opinions of authors expressed herein do not necessarily state or reflect those of the United States Government or any agency thereof. 
Environmental Sciences Division

HYDROPOWER CAPITAL AND O\&M COSTS: AN EXPLORATION OF THE FERC FORM 1 DATA

Gbadebo Oladosu ${ }^{1}$

Colin Sasthav ${ }^{1,2}$

${ }^{1}$ Oak Ridge National Laboratory

${ }^{2}$ Bredesen Center, University of Tennessee

February 2022

Prepared by

OAK RIDGE NATIONAL LABORATORY

Oak Ridge, TN 37831

managed by

UT-BATTELLE LLC

for the

US DEPARTMENT OF ENERGY

under contract DE-AC05-00OR22725

Approved for public release. 



\section{CONTENTS}

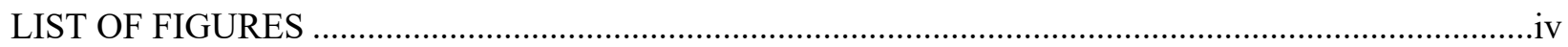

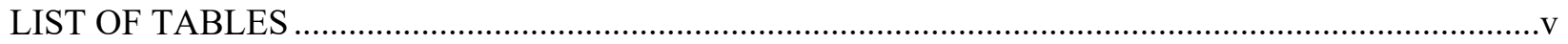

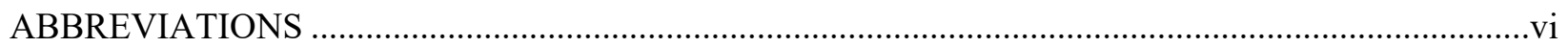

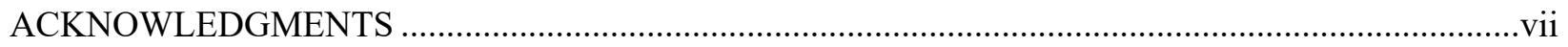

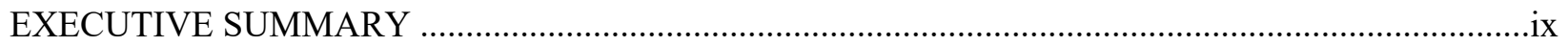

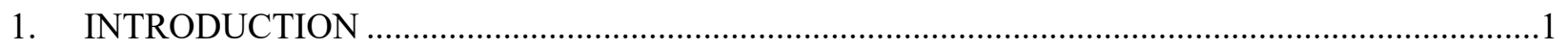

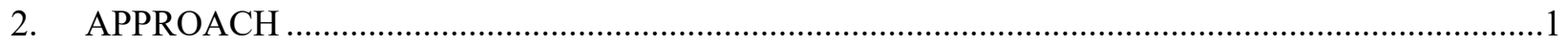

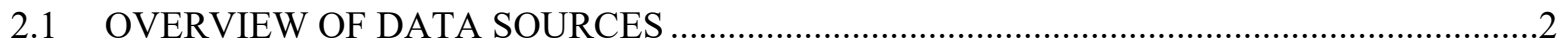

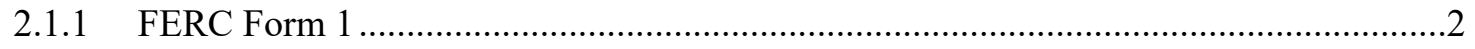

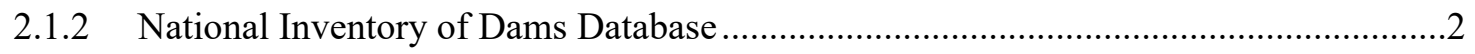

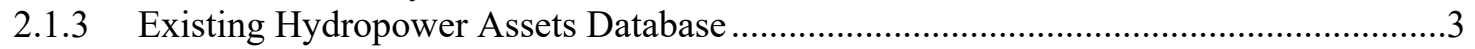

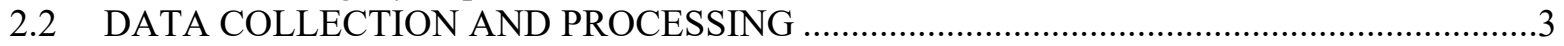

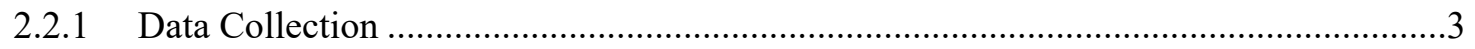

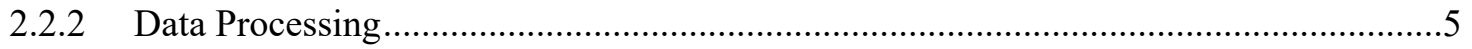

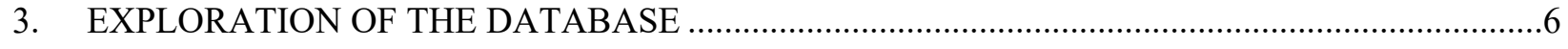

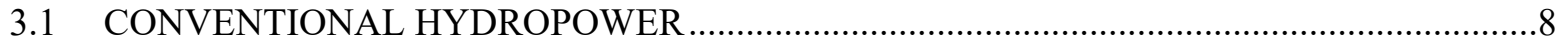

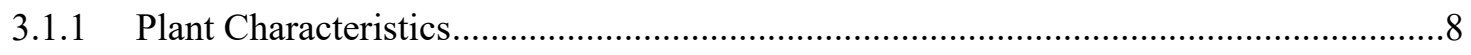

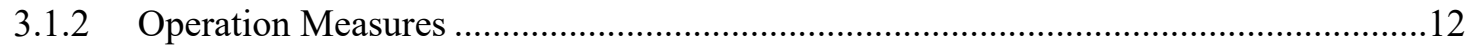

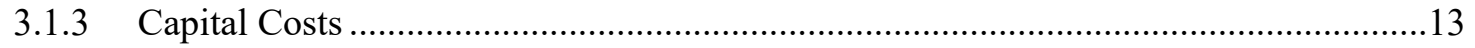

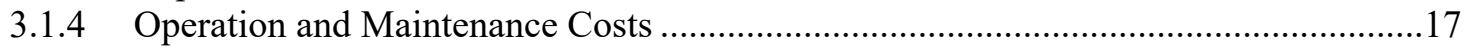

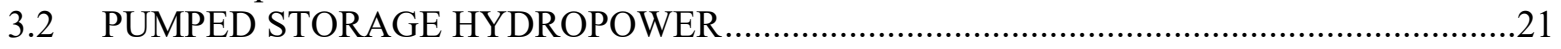

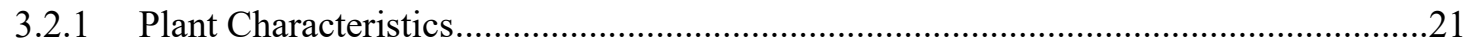

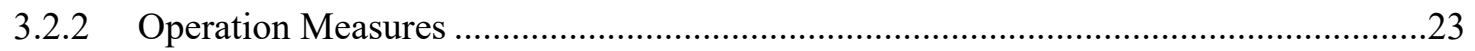

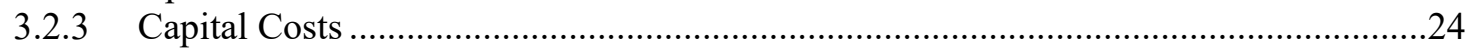

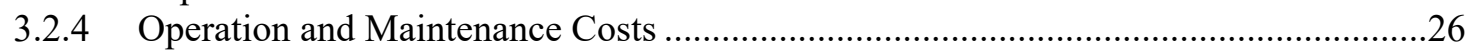

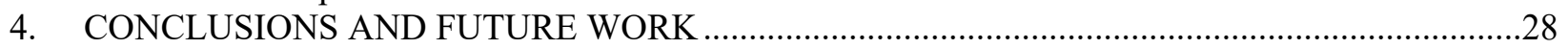

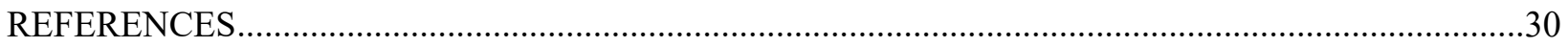

APPENDIX A. EQUATIONS IN THE BCM (Version 2) ..............................................................

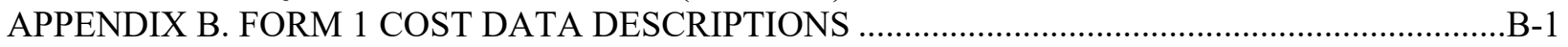




\section{LIST OF FIGURES}

Figure 1. Map of Form 1 hydropower and pumped storage plants by latest total capacity.

Figure 2. Total capacity for hydro and PSH plants for fully reported plants (have Form 1 entries

for 1994-2020) and all Form 1 entries (including those not fully reported).

Figure 3. Conventional hydropower capacity distribution comparison between the Form 1 database and the EHA database.

Figure 4. Distribution of Form 1 and EHA projects by main dam type $(\mathrm{RE}=$ earthen, $\mathrm{CN}=$ concrete, $\mathrm{ER}=$ rockfill, $\mathrm{MS}=$ masonry, $\mathrm{CB}=$ buttress, $\mathrm{PG}=$ gravity, $\mathrm{OT}=$ other, $\mathrm{VA}=$ arch, $\mathrm{MV}=$ multi-arch, $\mathrm{TC}=$ timber crib).

Figure 5. Histogram of Form 1 and EHA hydropower projects by construction year..............................11

Figure 6. Histogram of Form 1 and EHA hydropower projects by operating mode. ................................12

Figure 7. Capacity factor time series for hydropower plants by size class..........................................13

Figure 8. Capacity-weighted annual average number of employees for Large Hydro projects over the report period (1994-2020) for three size classes. ..................................................................13

Figure 9. Capital costs per kilowatt for the Small Plant and Large Hydro schedules by capacity

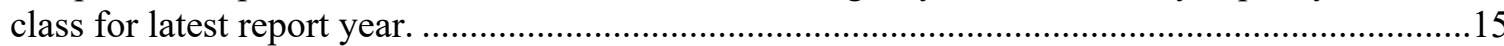

Figure 10. Capital cost breakdowns by components for Large Hydro plants for latest report year. ...........16

Figure 11. Capacity-weighted annual average capital costs for the Small Plant and Large Hydro

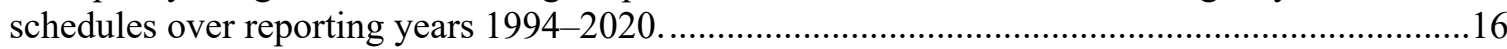

Figure 12. O\&M costs for the Small Plant and Large Hydro schedules by size class...............................18

Figure 13. O\&M cost account breakdowns for Large Hydro plants........................................................19

Figure 14. Average annual O\&M cost time series by size class for Small Plants and Large Hydro

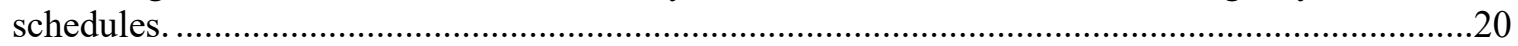

Figure 15. Capacity-weighted annual average O\&M costs per megawatt-hour for Form 1 hydropower plants by size class.........................................................................................20

Figure 16. PSH plant installed capacity distribution comparison between the Form 1 database and the EHA database.

Figure 17. PSH plant main dam type distribution comparison between the Form 1 and EHA databases $(\mathrm{ER}=$ rockfill, $\mathrm{CN}=$ concrete, $\mathrm{RC}=$ roller-compacted concrete, $\mathrm{RE}=$ earthen, $\mathrm{PG}=$ gravity, $\mathrm{OT}=$ others $)$.

Figure 18. PSH plant construction year distribution comparison between the Form 1 and EHA

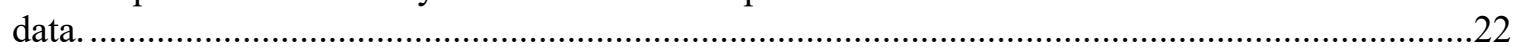

Figure 19. Capacity-weighted annual average capacity factor for PSH plants.....................................23

Figure 20. Capacity-weighted annual average number of employees for PSH plants..............................24

Figure 21. PSH plant latest capital cost distribution from the Form 1 data...............................................25

Figure 22. Breakdown of Form 1 capital cost accounts for the PSH plants. ..........................................25

Figure 23. Time series of Form 1 PSH plant average capital cost per kilowatt......................................26

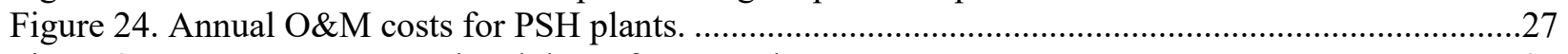

Figure 25. O\&M cost account breakdown for PSH plants. ................................................................27

Figure 26. Time series of annual average O\&M costs for PSH plants in terms of cost per kilowatt and cost per megawatt-hour. .28 


\section{LIST OF TABLES}

Table 1. Description of capital cost accounts from Form 1 data ..........................................................

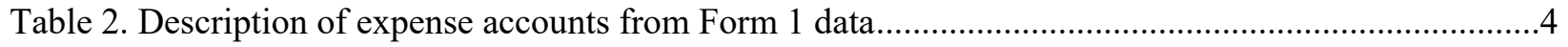

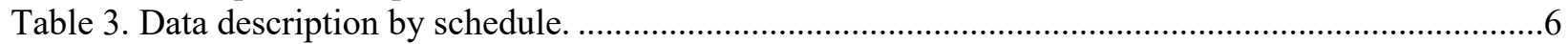

Table A.1. Empirical equations for initial cost of capital (ICC) and operation and maintenance $(\mathrm{O} \& \mathrm{M})$ costs by resource category from the baseline cost model, Version 2 [3] ...

Table B.1. Descriptions of the capital cost accounts for hydropower and pumped storage plants as reported in the Code of Federal Regulations [6] and the Form 1 submission document [7]

Table B.2. Descriptions of the operating expense accounts for hydropower and pumped storage plants as reported in the Code of Federal Regulations [6] and the Form 1 submission document [7] 


\section{ABBREVIATIONS}

BCM baseline cost model

CFR Code of Federal Regulations

CWAA capacity-weighted annual average

EHA Existing Hydropower Asset (database)

FERC Federal Energy Regulatory Commission

NID National Inventory of Dams

NIDID National Inventory of Dams national identifier

O\&M operation and maintenance

ORNL Oak Ridge National Laboratory

PSH pumped storage hydropower

ROR run of river

US United States

USACE US Army Corps of Engineers

WPTO Water Power Technologies Office 


\section{ACKNOWLEDGMENTS}

\section{Water Power Technologies Office, US Department of Energy}

The authors acknowledge and appreciate the Water Power Technology Office (WPTO) of the US Department of Energy for funding and oversight support for the project. In particular, the following individuals provided direct support for the Oak Ridge National Laboratory (ORNL) hydropower cost modeling project, as well as review and feedback on the study:

- Hoyt Battey, Program Manager for Strategic Planning, Analysis and Outreach

- Kathryn Jackson, Project Engineer

\section{Oak Ridge National Laboratory, US Department of Energy}

The following individuals from ORNL provided operational support and technical support for the project:

- Shih-Chieh Kao, ORNL Program Manager for WPTO Projects

- Debjani Singh, ORNL HydroSource Principal Investigator

\section{Technical Reviewer}

- Rocio Uria-Martinez

\section{Technical Editor}

- Charlie Horak 
Approved for public release. viii 


\section{EXECUTIVE SUMMARY}

Hydropower cost data is necessary for investment and decision-making by plant owners, project developers, technology developers, and regulators in the industry. This report explores the potential for using responses from the Federal Energy Regulatory Commission's (FERC's) "Electric Utility Annual Report," also known as FERC Form 1, as a cost database for conventional and pumped storage hydropower (PSH).

The report outlines the process used to compile an easy-to-access database from the original FERC Form 1 data and discusses the historical cost/performance data. The steps for developing the database include downloading the annual FoxPro files from the FERC website (FERC, 2020) ${ }^{1}$, reading them into an Excel format, and reconciling naming issues across years, repeated entries, and shared assets, among others. The cleaned and compiled Form 1 database is available on Oak Ridge National Laboratory's (ORNL's) HydroSource website ${ }^{2}$. For this report, the compiled Form 1 database was linked to two other hydropower databases, the National Inventory of Dams and the ORNL Existing Hydropower Assets, that provide additional information on the characteristics and other features of plants in the Form 1 data. Explorations of the plant characteristics, performance, capital costs, and operation and maintenance (O\&M) cost data in the combined database were presented separately for conventional hydropower and PSH projects.

Form 1 has several advantages as a hydropower cost database. First, the cost data is reported directly by plant owners. Second, Form 1 provides cost breakdowns of capital and operating costs for large conventional and PSH plants enabling more detailed tracking of hydropower costs compared with typical total cost estimates. Third, although the Form 1 data is not reported by all operational hydropower plants in the United States, the available data represents a wide range of plant characteristics and a sizable proportion of the hydropower fleet (61\% of PSH plants and $22 \%$ of conventional hydropower plants by capacity). The lower proportion of the conventional hydropower fleet is because Form 1 reporting requirements apply only to private utilities that meet given size thresholds, leaving out federally owned facilities and many smaller hydropower plants.

However, several challenges could be addressed to improve the usability of the Form 1 data for hydropower cost analyses. First, the capital cost data is reported as running book cost accounts, so that costs cannot be fully adjusted for inflation since nominal costs incurred in different years are combined in each year and most of the plants were built before the initial report year (1994). Second, the publicly available Form 1 data does not contain data descriptions and includes many cases of inconsistent plant identifiers across years, so the data requires manual interpretation and processing. Third, federal agencies, such as the US Bureau of Reclamation and the US Army Corps of Engineers, are not required to report to Form 1 data, which excludes a significant portion of the existing hydropower fleet from the database ( $16 \%$ of PSH plants and $48 \%$ of conventional hydropower plants by capacity).

Overall, the Form 1 cost database represents a unique, publicly available database on hydropower asset capital and O\&M costs. This report leads to a compiled database for the reporting years 1994 to 2020 that helps resolve issues with accessibility and use of the FERC Form 1 data by hydropower plant owners, project developers, technology developers, and regulators. In combination with other hydropower databases, this data would help track the cost and performance of plants included in the database, particularly the O\&M costs and performance data, which are updated on an annual basis. The data also provides a sizable sample for generating potential insights into hydropower industry trends at large.

\footnotetext{
${ }^{1}$ https://www.ferc.gov/industries-data/electric/general-information/electric-industry-forms/form-1-electric-utilityannual

${ }^{2}$ https://doi.org/10.21951/ORNLHCMFORM1COST/1844097
}

Approved for public release. 


\section{INTRODUCTION}

Hydropower stakeholders require cost information to prioritize development opportunities, plan operation and maintenance (O\&M) efforts, identify potential innovations to reduce costs, set benchmarks for future project development, and track industry trends. However, hydropower costs are highly site specific because plants must accommodate unique site conditions and optimize power and nonpower benefits. In addition, the potential hydropower sites in the United States have much smaller and more variable water resources and face proportionately more costly environmental requirements relative to most existing hydropower sites [1]. Thus, accurate estimates of costs for future hydropower projects require details about project features, site conditions, water resource potential, and regulatory requirements, among others.

The "Electric Utility Annual Report" published by the Federal Energy Regulatory Commission (FERC), known as FERC Form 1, is a promising basis for developing a detailed, accessible, and comprehensive hydropower cost database. Form 1 is submitted annually, provides a uniform system of accounting across FERC-regulated plants, and is publicly available. A previous effort by Oak Ridge National Laboratory (ORNL) used data from FERC Form 1 and other sources to estimate a baseline cost model $(\mathrm{BCM})^{3}[2]$. The existing version of the model, BCM (Version 2), includes empirical models of initial capital costs for six different project types, as well as a single equation of O\&M costs [3]. The project types include new stream-reach development, non-powered dams, canals/conduits, pumped storage hydropower (PSH), unit additions, and generator rewinds. The cost equations (see Appendix A) are specified as functions of plant capacity $(\mathrm{P})$ and hydraulic head $(\mathrm{H})$.

In addition to the aggregate costs used in the $\mathrm{BCM}$, the Form 1 data includes information on various hydropower cost components. This report aims to explore the potential of the Form 1 data to provide insights into hydropower cost trends and support detailed cost modeling efforts. The report visualizes the Form 1 hydropower cost data and documents its advantages and limitations, leading to an accessible database of these records that might increase its use by industry stakeholders. Although the scope of the Form 1 data covers many electricity generation technologies, this report is limited to conventional hydropower projects (referred to as "hydro") and PSH projects (referred to as "PSH"). Section 2 describes the approach used for collecting, processing, and analyzing the Form 1 and other relevant databases used in this report. Section 3 presents an exploration of the available Form 1 data from 1994-2020 with visualizations of plant characteristics, capital costs, and O\&M costs, among others. Finally, Section 4 summarizes the advantages and disadvantages of using the Form 1 data for estimating hydropower costs and provides recommendations for future work.

\section{APPROACH}

This section describes the collection, cleaning, and processing of the Form 1 data for conventional hydropower and PSH plants. The Form 1 data was linked with two databases to provide additional information on the site and plant characteristics: (1) the National Inventory of Dams (NID) database from the US Army Corps of Engineers [4] and (2) the Existing Hydropower Asset (EHA) database from ORNL [5].

\footnotetext{
${ }^{3}$ https://www.osti.gov/biblio/1244193-hydropower-baseline-cost-modeling-version
} 


\subsection{OVERVIEW OF DATA SOURCES}

\subsubsection{FERC Form 1}

FERC Form 1, also known as the "Electric Utility Annual Report," is "a comprehensive financial and operating report submitted for Electric Rate regulation and financial audits" [6]. Therefore, FERC Form 1 is primarily an accounting document, and the requirements for reporting are described in the Code of Federal Regulations (CFR) Subchapter C, Part 101, "Uniform system of accounts prescribed for public utilities and licensees subject to the provisions of the federal power act" (hereafter referred to as the "Uniform System of Accounts") [6]. All FERC-regulated major electric utilities submit this form electronically to FERC. FERC defines major utilities as utilities, licensees, and other parties with sales or transmission service in the previous three years that exceed one of the following [7]:

- one million megawatt-hours or more,

- 100 megawatt-hours of annual sales for resale,

- 500 megawatt-hours of annual power exchange delivered, or

- 500 megawatt-hours of annual wheeling for others (deliveries plus losses).

Based on this definition, FERC Form 1 does not apply to many small plant owners (utilities, municipalities, or private entities) or federal agencies, such as the US Army Corps of Engineers (USACE), the Tennessee Valley Authority, or the US Bureau of Reclamation. These federal agencies are some of the largest hydropower owners, representing approximately $48 \%$ of the US conventional hydropower capacity and 16\% of PSH. Utilities submit Form 1 data on the FERC website [7], and the resulting data can be viewed using FERC's viewer software or downloaded as a zipped Visual FoxPro database for each year (containing file formats DBF, CDX, FPT, etc.).

\subsubsection{National Inventory of Dams Database}

The NID database is compiled by USACE based on information from various sources and is publicly available ${ }^{5}$ ]. The NID contains dam characteristics data for more than 90,000 dams that meet any of the following criteria [4]:

1. high hazard potential classification: loss of human life is likely if the dam fails;

2. significant hazard potential classification: no probable loss of human life but can cause economic loss, environmental damage, disruption of lifeline facilities, or impact other concerns;

3. equals or exceeds 25 feet in height and exceeds 15 acre-feet in storage; or

4. equals or exceeds 50 acre-feet storage and exceeds 6 feet in height.

Dams in the NID database are indexed by an alphanumeric national identifier (NIDID) that starts with the state two-letter code based on location, typically followed by five numbers. A given hydropower project can include one or more structures in the NID, such as main and auxiliary dams. The NID includes a wide array of dam characteristics, including location, ownership type, purpose, reservoir characteristics, regulating authority, hazard potential (which refers to the potential for losses in case of dam failure, not the probability of dam failure), and inspection data, among others. Since civil works and structures are

\footnotetext{
${ }^{4}$ https://www.ferc.gov/industries-data/electric/general-information/electric-industry-forms/form-1-electric-utilityannual

$\underline{{ }^{5} \text { https: } / / n i d . u s a c e . a r m y . m i l / \# l}$
}

Approved for public release. 
significant cost components of hydropower development, the NID provides valuable information about the characteristics of these structures that can be linked to the Form 1 cost data.

\subsubsection{Existing Hydropower Assets Database}

The EHA database [5] is compiled by ORNL and is available publicly on the HydroSource ${ }^{6}$ platform [8]. It is a comprehensive point-based database describing the 2,298 operational hydropower plants at the time of writing this report. The data fields captured in the EHA include plant location, power generation characteristics, and regulatory agencies. The entries are indexed by an EHA plant ID and are connected to an NIDID. Since Form 1 data is self-reported and vulnerable to input inconsistencies, the EHA database provides a helpful benchmark for connecting Form 1 entries to well-established plant information.

\subsection{DATA COLLECTION AND PROCESSING}

\subsubsection{Data Collection}

The Form 1 data from 1994-2020 was compiled from the FERC website by downloading the zipped Visual FoxPro data files for each year. The unzipped data for each year was read and compiled into an Excel Workbook using a Microsoft VBA (Visual Basic for Applications) script. Since the compiled data did not include metadata, interpretation of the tabular data is based on information from the "Uniform System of Accounts" document and the Form 1 submission document.

The Form 1 data includes three schedules (forms/pages in the data submission document) that contain hydropower cost information. These schedules are as follows:

- Generating Plant Statistics (Small Plants) — contains plants with less than $10 \mathrm{MW}$ of nameplate hydropower capacity. Since this schedule also contains internal combustion and gas turbine plants with less than $25 \mathrm{MW}$ of capacity, the hydropower plants were identified using the fuel type column (including water, hydro, and run-of-river) and by matching the plants with those in the EHA data. No pumped storage plants were identified in this sheet. This schedule is called Small Plants throughout this report.

- Hydroelectric Generating Plant Statistics (Large Plants) — contains plants that report under the large hydroelectric plants form, which pertains to plants with greater than $10 \mathrm{MW}$ of nameplate capacity. However, several plants reported in this schedule have less than $10 \mathrm{MW}$ of total capacity. This schedule is called Large Hydro throughout this report.

- Pumped Storage Generating Plant Statistics (Large Plants) — contains pumped storage plants with greater than $10 \mathrm{MW}$ of installed nameplate capacity. This schedule is called PSH Plants in this report.

The data fields available depend on the schedule. All three schedules have total capital costs, total operating costs, and information on plant statistics, including total capacity, peak demand, operating hours, net generation, installation year, and operating mode. However, only the Large Hydro and PSH Plants include capital and operating costs broken down into different components. The rules regarding how cost information is recorded in these accounts are discussed briefly in the following, but readers are referred to the "Uniform System of Accounts" document for more information [6].

${ }^{6}$ https://hydrosource.ornl.gov/datasets

Approved for public release. 
Capital cost accounts contain the book costs (the original cost of the unit without deductions for depreciation, amortization, or other purposes) of the electric plant's "retirement units." A retirement unit is an asset (e.g., turbine) that will eventually be retired (i.e., taken out of service and sold or discarded). In short, the accounts record the balance of cash invested into plant assets. When a retirement unit is purchased, the original cost of the retirement unit is added to the account. When the retirement unit is retired, the book cost is subtracted from the account. Therefore, the cost accounts represent the capital invested in the current assets of the plant, unadjusted for inflation during each report year. Table 1 shows the capital cost categories in the Form 1 data, with a brief description of the assets captured in each category. Appendix B contains a complete description of the cost components attributed to each capital account, as listed in the "Uniform System of Accounts."

Expense accounts are records of O\&M costs for a given year and are assumed to be reported in the dollar value of the report year. Table 2 shows the categories included in the expense accounts data and the corresponding asset classes. Appendix B contains a complete description of each category for the expense accounts.

Table 1. Description of capital cost accounts from Form 1 data

\begin{tabular}{cccl}
\hline Category & Data label & Account \# & \multicolumn{1}{c}{ Full account title } \\
\hline Land & cost_land & 330 & Land and land rights \\
Structures & cost_structures & 331 & Structures and improvements \\
Facilities & cost_facilities & 332 & Reservoirs, dams, and waterways \\
Wheels & cost_wheels & 333 & Water wheels, turbines, and generators \\
Electric & cost_electric & 334 & Accessory electric equipment \\
Misc. equipment & cost_misc_equipment & 335 & Miscellaneous power plant equipment \\
Equipment & cost_equipment & N/A & Sum of accounts 333-335 (hydro only) \\
Roads & cost_roads & 336 & Roads, railroads, and bridges \\
Retirement & asset_retire_cost & 337 & Asset retirement costs for hydraulic production plant \\
\hline
\end{tabular}

Table 2. Description of expense accounts from Form 1 data

\begin{tabular}{cccl}
\hline Category & Data field & Account \# & \multicolumn{1}{c}{ Full account title } \\
\hline & & \multicolumn{3}{c}{ Operation } \\
\hline Superv\&Eng & expns_operations & 535 & Operation supervision and engineering \\
Water Use & expn__water_pwr & 536 & Water for power \\
Hydraulic & expns_hydraulic & 537 & Hydraulic operation \\
Electric & expns_electric & 538 & Electric operation \\
Miscellaneous & expns_generation & 539 & Miscellaneous hydraulic power generation \\
Rents & expns_rents & 540 & Rents \\
& & Maintenance \\
\hline Superv\&Eng & expns_engnr & 541 & Supervision and engineering \\
Structures & expns_structures & 542 & Structures \\
Dams & expns_dams & 543 & Reservoirs, dams, and waterways \\
Electric & expns_plant & 544 & Electric plant \\
Miscellaneous & expns_misc_plant & 545 & Miscellaneous hydraulic plant \\
Storage & expns_pump_strg & N/A & *Pumped storage expenses (PSH only) \\
Pumping & pumping_expenses & N/A & *Cost of energy used for pumping (PSH only) \\
\hline
\end{tabular}

*These accounts are not included in the Code of Federal Regulations, so definitions are based on the Form 1 document.

The Form 1 data tables also include their own data fields for total and per kilowatt costs. For the visualizations in Section 3, total cost and cost per kilowatt information were recalculated using the 
accounts listed in Table 1 and Table 2. This analysis focused on operational asset costs, so asset retirement costs were not included in the total costs or cost breakdowns, which facilitated the need for custom calculations. In addition, the values reported in Form 1 were subject to user input error, so the custom calculations provided another level of error checking.

\subsubsection{Data Processing}

Several processing steps were necessary to obtain usable information from the extracted Form 1 data. First, extraneous rows and columns that did not provide useful cost and plant characteristics information were removed. These included entries without decipherable plant names or for which total capacities, total capital costs, and total operating expenses could not be obtained. Next, inconsistencies in the records were manually cleaned, including changes in plant naming conventions across report years, repeated entries, missing data fields, and general user input errors (i.e., typos). When possible, missing qualitative information was interpreted based on other entries for the same project. The primary identifier in the Form 1 data is the plant name, so the manual cleaning process aimed to match plant names across report years. However, for plants with multiple owners, which was often the case for PSH plants, all of the owners had to submit cost information for the assets under their management, leading to multiple entries for a given plant and year. In addition, owners can change across years, leading to some entries describing the total plant costs and some describing owner-specific assets. Additionally, projects with multiple powerhouses presented additional complexity. These entries were handled on a case-by-case basis. Entries describing the total plant assets were preferred, and only entries paired with an entry in the EHA database were kept.

Given that the Form 1 data is reported manually, it was also essential to identify and remove outliers that were likely a result of entry error. Hydropower plants can face large cost overruns from factors such as structural failures or foundation challenges, so the goal was to identify likely instances of entry errors rather than statistical outliers. Thus, capital and operating cost per kilowatt thresholds were determined by visual examination of the data. The outlier thresholds for hydropower projects were $\$ 25,000 / \mathrm{kW}$ for capital costs and $\$ 500 / \mathrm{kW}$ for O\&M costs, and there were no visual outliers for pumped storage capital or operating costs. Only 24 hydropower cost outliers were removed using this method, all within the Small Plants schedule.

The cleaned Form 1 data entries were connected to the NID and EHA databases to produce a single linked database. Form 1 is indexed by plant name, whereas NID and EHA are primarily indexed by custom ID codes (although plant names were also available). Often the Form 1 plant name did not match with plant names from EHA, so the pairing was done manually in those cases. The respondent's name, the installation year, and the capacity were used as clues to pair entry names across these databases. Any entries that could not be paired to an EHA entry were removed; however, entries not connected to an NID entry were kept since plants might not be connected to a dam within NID. When multiple NID entries were connected to a plant from Form 1, only the primary dam used to divert water to the powerhouse was used in the analysis.

Finally, the cost data was escalated to the 2020 dollar year (\$2020) using the US Bureau of Reclamation's Construction Cost Trends data [9], which documents cost indices for various construction-related categories. The annual composite trend, which averages these indices across categories, provides an industry-wide index for construction costs during each year. The multiplication factors used to scale costs between dollar years were generated by dividing the 2020 composite index by the composite index of the corresponding dollar year. Operating expenses were assumed to be reported in the dollar year of the corresponding Form 1 report year, so the escalation factor was simply based on the report year. The capital costs described the book costs of the plant assets at each report year, meaning they often changed between report years. Several major plant assets, including the dam, spillways, and conveyances, were

\section{Approved for public release.}


expected to be installed during the construction year, while others, such as electro-mechanical equipment, are expected to change over time. However, the earliest Form 1 report year was 1994, which precluded the ability to pair itemized costs to the appropriate dollar year for plants constructed before 1994. Based on language from the Code of Federal Regulations, it is assumed that plants constructed before 1994 estimated capital costs in the dollar year of the earliest Form 1 submission. So, the process for escalating capital costs for each plant consisted of (1) setting a base year corresponding to the first Form 1 report year for the plant, (2) setting a base cost by escalating the first reported capital cost from the base year to $\$ 2020$, (3) escalating the year-to-year change in capital cost based on the Form 1 report year, and (4) cumulating the escalated increments in (3) and adding to base cost in (2) to obtain an escalated capital cost for each year.

\section{EXPLORATION OF THE DATABASE}

This section aims to review and illustrate the contents of the compiled and cleaned Form 1 database. To this end, the following subsections highlight (1) how well the Form 1 plants represent the population of hydropower plants in the United States, (2) the categorical breakdowns of capital and operating costs for these plants, and (3) how these costs have changed over time. The Form 1 database with EHA and NID identifiers as compiled for this report, but without EHA and NID specific data fields, can be found on HydroSource ${ }^{7}$.

The database contains entries from 1994-2020 across three relevant schedules: Small Plants, Large Hydro, and PSH Plants. The data from each of these schedules are described in Table 3. Although Small Plants and Large Hydro schedules are supposed to be limited to $<10 \mathrm{MW}$ and $>=10 \mathrm{MW}$, respectively, there is overlap between their capacity ranges. The Small Plants schedule reports only total capital and O\&M cost data, whereas Large Hydro and PSH Plants also report breakdowns of capital and O\&M costs by components. When total capital or O\&M costs are reported for the following sections, the Small Plants and Large Hydro data sets are combined into one data set and classified according to the following size classes: $<10 \mathrm{MW}, 10-30 \mathrm{MW}, 30-100 \mathrm{MW}$, and $>100 \mathrm{MW}$. The $<10 \mathrm{MW}$ class contains plants from the Small Plants and Large Hydro schedules. However, when presenting cost breakdowns, which are available only for the Large Hydro and PSH Plants schedules, the Small Plants are not included and the size classes for hydro projects are: $<30 \mathrm{MW}, 30-100 \mathrm{MW},>100 \mathrm{MW}$.

Table 3. Data description by schedule. Records are provided by each plant for each report year (1994-2020), although not all plants report for the full time period. Cumulative capacity and capacity ranges are determined using the latest reported capacity for each plant.

\begin{tabular}{lcccc}
\hline \multicolumn{1}{c}{ Schedule } & Record count & Unique plant count & $\begin{array}{c}\text { Plant capacity } \\
\text { range (MW) }\end{array}$ & $\begin{array}{c}\text { Cumulative } \\
\text { capacity (MW) }\end{array}$ \\
\hline Small Plants & 1,227 & 96 & $0.25-9.54$ & 316 \\
Large Hydro & 5,940 & 287 & $0.93-675$ & 17,274 \\
PSH Plants & 381 & 23 & $31-3010$ & 13,349 \\
\hline
\end{tabular}

The rest of this report focuses on either a single year or all available data years. Since capital cost information is reported as the running balance of plant asset book costs, only the latest available data year

\footnotetext{
${ }^{7}$ https://doi.org/10.21951/ORNLHCMFORM1COST/1844097
}

Approved for public release. 
is used for capital cost information. O\&M costs are unique to each year, so all available data years are included. Each value is escalated to $\$ 2020$, as previously described.

Figure 1 shows the hydropower and pumped storage plants from all three schedules mapped to their locations by the latest reported total capacity. The size of the dots indicates the capacity categories, and colors indicate the type of plant (blue = conventional hydropower; orange = pumped storage). The spatial distribution of plants is representative of the densely populated hydropower plants along the east and west coasts, although Form 1 underrepresents the sparsely populated plants in the Missouri, Upper Colorado, and Lower Colorado watersheds. This is likely because Form 1 does not include plants owned by federal agencies, such as USACE and the US Bureau of Reclamation, which are active in these areas. For a complete map of hydropower plants by owner, readers are referred to Samu et al. [10].

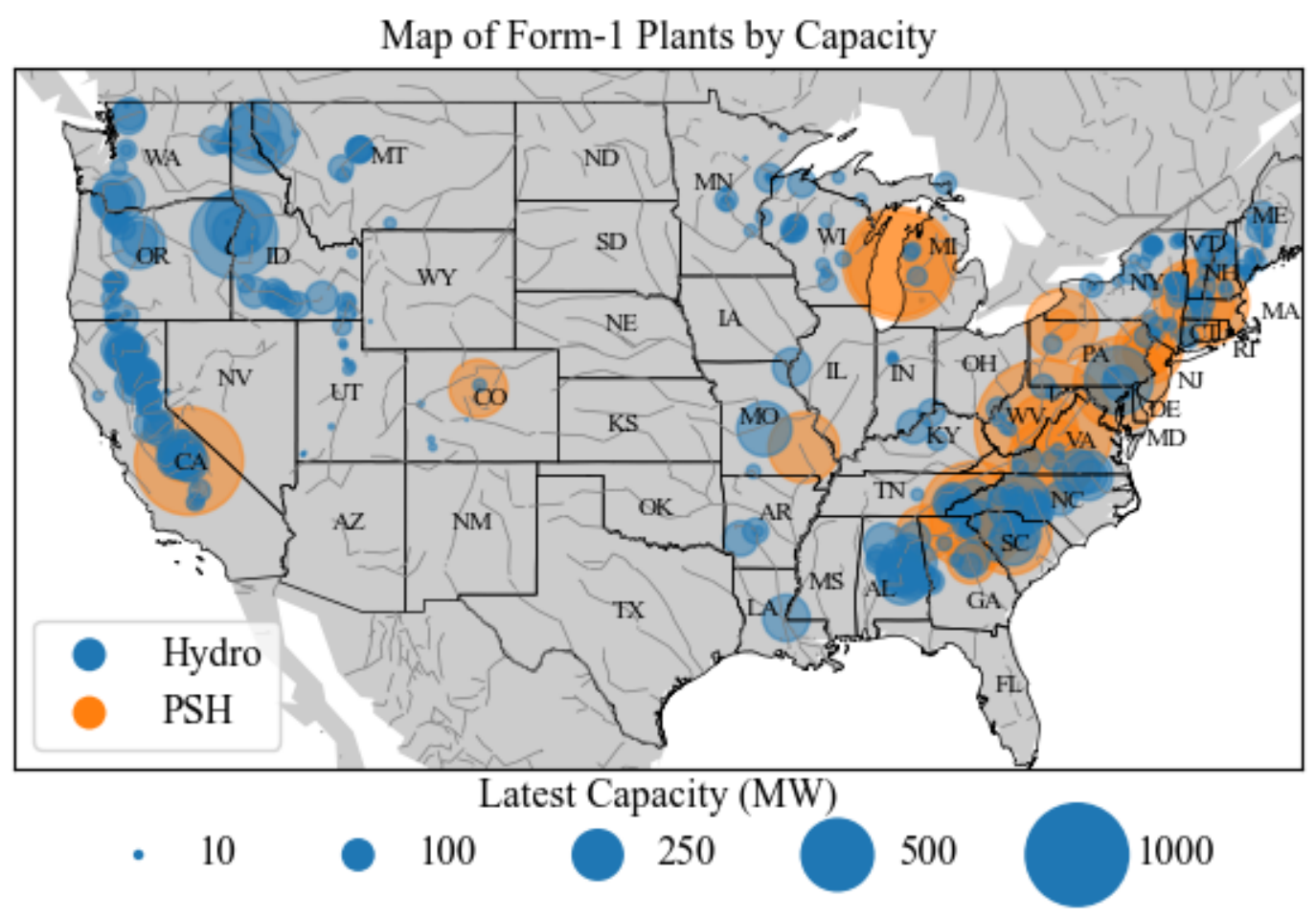

Figure 1. Map of Form 1 hydropower and pumped storage plants by latest total capacity.

The following sections explore plant characteristics, capital costs, and operating costs separately for conventional hydropower and PSH. These are represented as distribution and time series plots. Note that variability in the time series plots generated using the Form 1 data might result from (1) actual changes in the plant's data because of retirements, upgrades, or other reasons or (2) changes in the number and composition of reporting utilities because of eligibility thresholds for FERC Form 1 reporting or new plants. Thus, this variability might be a function of additional entries rather than true year-to-year variability in individual plant data. These potential sources of variability are illustrated in Figure 2, which shows the total annual capacity of reporting plants for conventional hydropower and pumped storage plants. The two lines in each chart represent the total capacity for all reporting plants in each year and the total capacity for plants with data in all years (i.e., fully reported). For conventional hydropower plants, Figure 2 shows that the total conventional hydropower capacity reported in each year was between 12 GW and $17 \mathrm{GW}$ over the 1994-2020 period, with about $10 \mathrm{GW}$ of this capacity from projects that reported data for all years. For pumped storage projects, the reported total capacity for each year was between $6 \mathrm{GW}$ and $11 \mathrm{GW}$, with about $6 \mathrm{GW}$ from projects that reported data for all years. 
Comparatively, the total US capacity was about $80 \mathrm{GW}$ for conventional hydropower and about $22 \mathrm{GW}$ for PSH projects in 2020 [5]. In addition, Figure 2 shows a slight upward trend in the capacity of conventional hydropower plants that reported data for all years, whereas there were significant fluctuations in the corresponding capacity plot for pumped storage plants. Each year's reported capacities show significant variation over time for both types of projects, with pumped storage plants particularly showing a significant drop between 2000 and 2015. For this report, all available data are discussed, but future efforts using this data might need to account for the different sources of changes in reported project data across years.

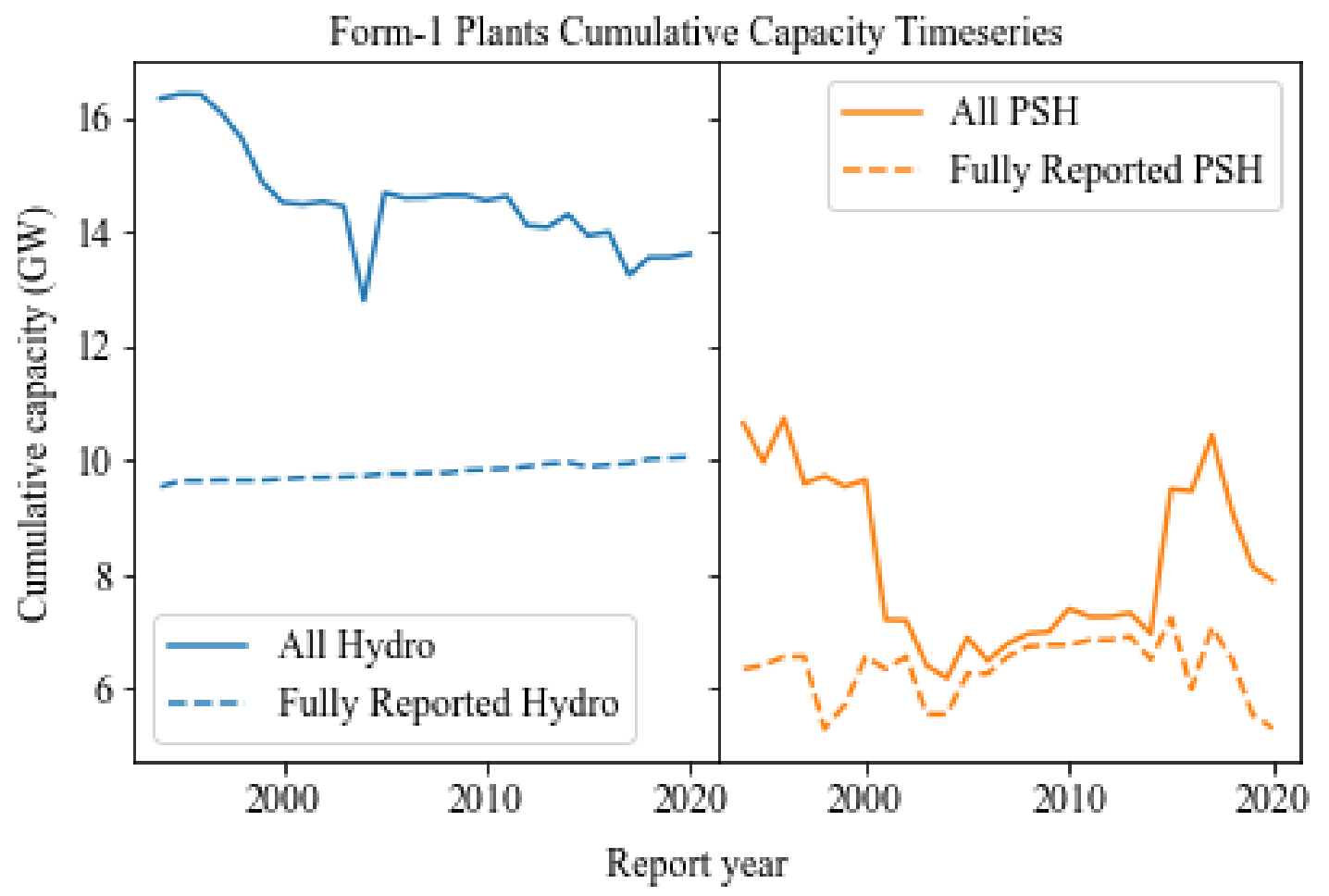

Figure 2. Total capacity for hydro and PSH plants for fully reported plants (have Form 1 entries for 19942020) and all Form 1 entries (including those not fully reported).

The following section uses capacity-weighted annual averages (CWAAs) when aggregating variables into a time series. Using a capacity-weighted average instead of an arithmetic mean is common practice in hydropower cost modeling to better represent the importance of plant capacity on cost. The equation used to calculate CWAA for a given year is

$$
C W A A=\frac{\sum_{i=1}^{n} \text { Capacity }_{i} \text { Variable }_{i}}{\sum_{i=1}^{n} \text { Capacity }_{i}}
$$

\subsection{CONVENTIONAL HYDROPOWER}

\subsubsection{Plant Characteristics}

Given that the Form 1 data is a sample of the entire hydropower fleet (given in the EHA data), it is essential to understand how representative the Form 1 data is of the fleet's characteristics. The combined 
Form 1, EHA, and NID database provides information for four plant characteristics, which are compared with those in the EHA data in this section. Figure 3 compares the distribution of installed capacities from the Form 1 data with those from the EHA database. In the EHA database, some plants have both conventional hydropower and pumped storage capabilities. Plants with any pumped storage capabilities are categorized as PSH plants and are not included in this section, leaving 2,255 operational conventional hydropower plants from EHA compared with 287 from Form 1. Form 1 shows an overrepresentation of projects between approximately $8 \mathrm{MW}$ to $400 \mathrm{MW}$ within the sample and does not represent projects under $250 \mathrm{~kW}$ or above $1000 \mathrm{MW}$. These observations reflect the focus of requirements for Form 1 data submission on major private utilities, excluding many small hydropower plants and federal electricity utilities that tend to operate larger plants. More than $70 \%$ of the 2,255 EHA projects used for comparison here have $<10 \mathrm{MW}$ of capacity. However, the Form 1 data provides a relatively wide range of capacities that could prove useful for analyzing plant costs by size class.

\section{Hydro Capacity Distribution Comparison}

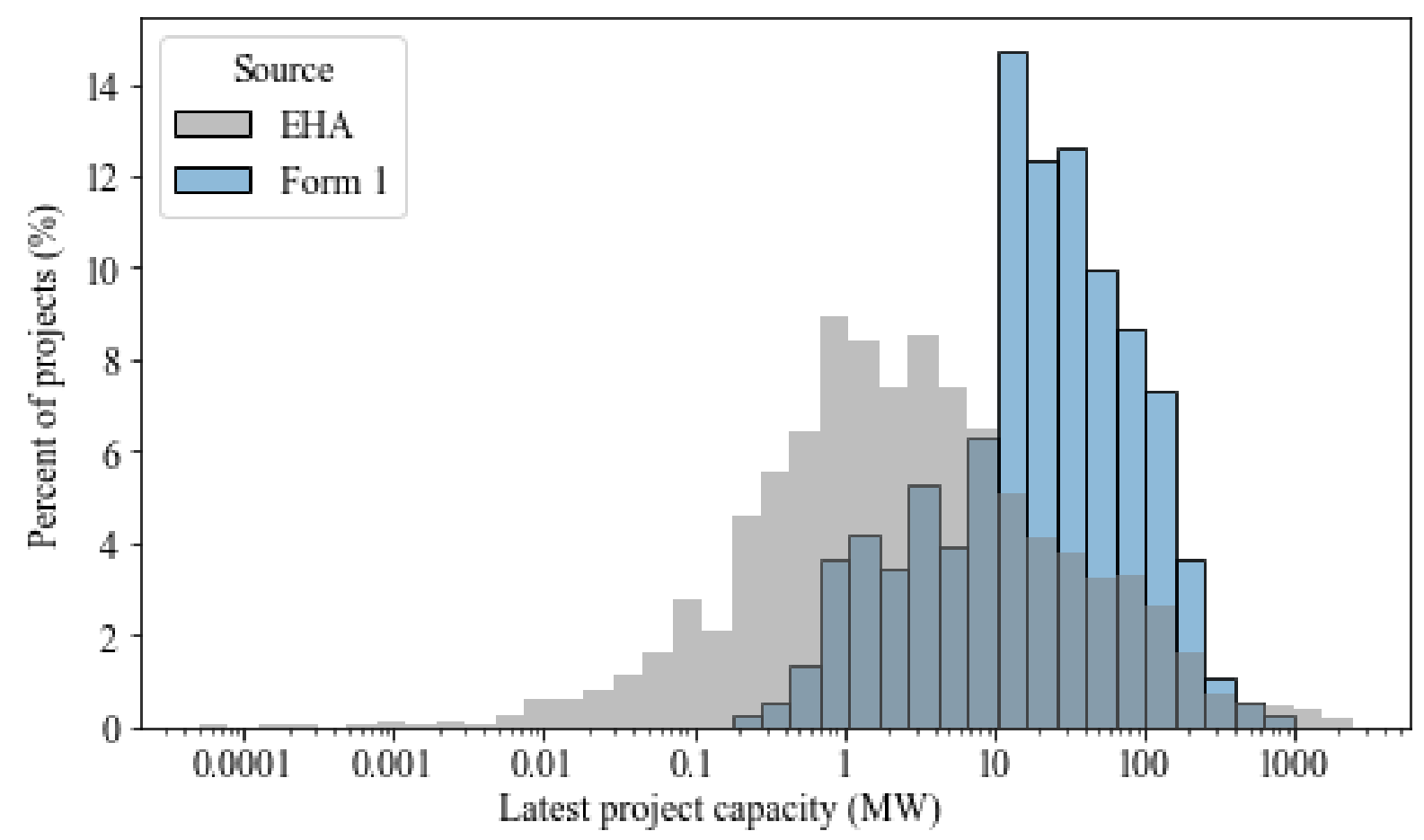

Figure 3. Conventional hydropower capacity distribution comparison between the Form 1 database and the EHA database.

Civil works, including foundations, dams, and additional structures, are usually the largest cost components of a hydropower project. Dam requirements are determined by a host of factors, including site conditions, project design requirements, safety, other regulatory requirements, other uses of the dam, and water resources, among other factors. In turn, the dam type determines the types and quantities of materials needed for civil works and the costs. The NID reports dam types based on concatenated strings of two-letter codes listed in order of importance, so the first two-letter code represents the primary dam type. Figure 4 shows that the distributions of primary dam types are similar for the Form 1 and EHA databases, with earthen, concrete, and gravity being the main types. There is a slight underrepresentation of earthen and overrepresentation of concrete dam types in the Form 1 data relative to the EHA data. 


\section{Hydro Projects by Main Dam Type}

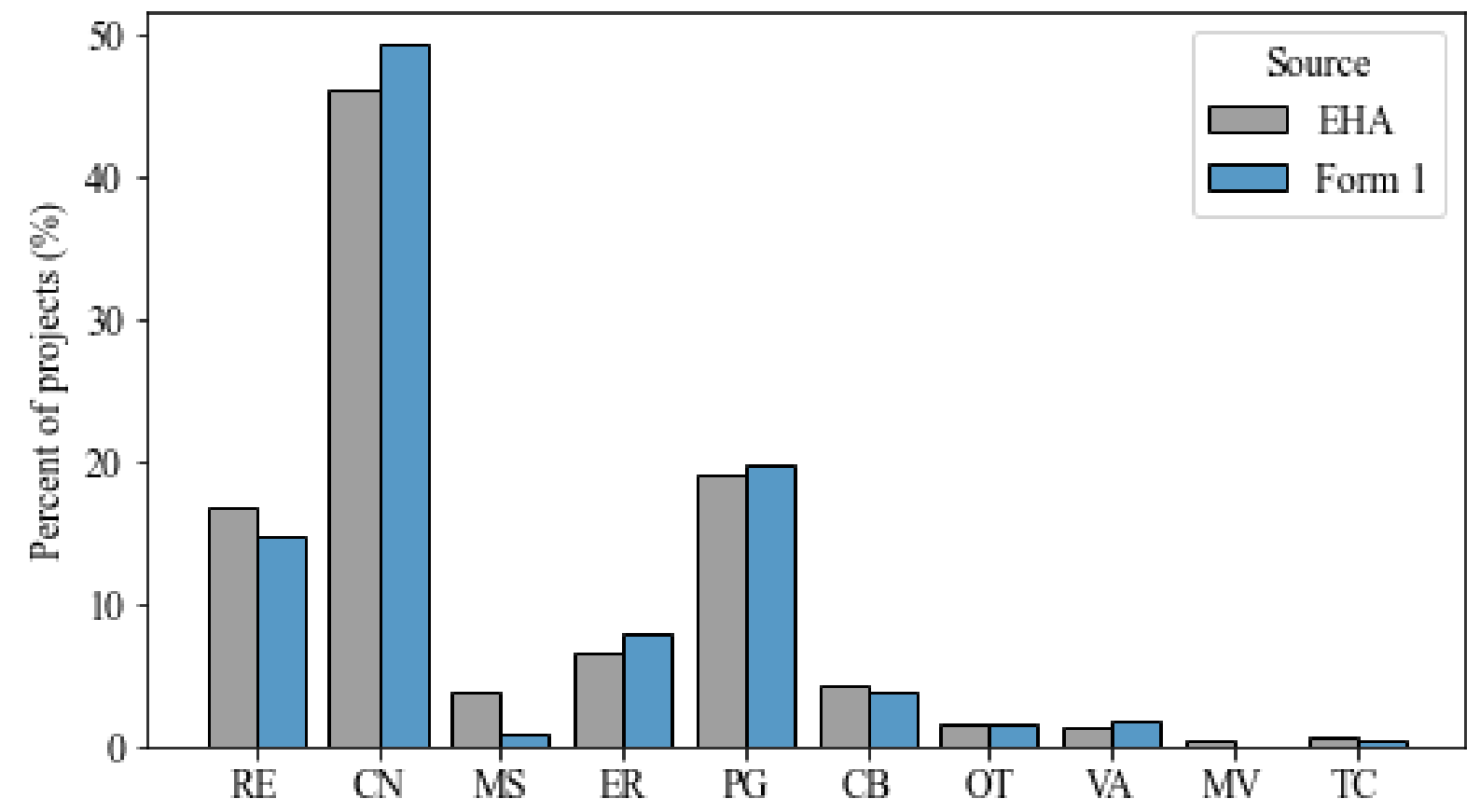

Figure 4. Distribution of Form 1 and EHA projects by main dam type $(\mathrm{RE}=$ earthen, $\mathrm{CN}=$ concrete, $\mathrm{ER}=$ rockfill, $\mathrm{MS}=$ masonry, $\mathrm{CB}=$ buttress, $\mathrm{PG}=$ gravity, $\mathrm{OT}=$ other, $\mathrm{VA}=\operatorname{arch}, \mathrm{MV}=$ multi-arch, $\mathrm{TC}=$ timber crib).

Plant age is an important factor for hydropower management because of the long life of dams and hydropower assets, the role of prolonged wear and tear as a driver of O\&M costs, and the changing regulatory environment that may affect the viability of a project for relicensing at the end of its current license. Figure 5 compares the distribution of plants over the construction year in the Form 1 data with those in the EHA data. The Form 1 data has a larger proportion of projects built during the 1920-1930 and 1950-1960 periods than the EHA data. This likely reflects the general hydropower development trend where projects get smaller over time. This is because the best projects, with larger capacities and significant economies of scale, are built first, leaving smaller sites that are developed over time as technology innovation counteracts their cost disadvantages relative to larger sites. 


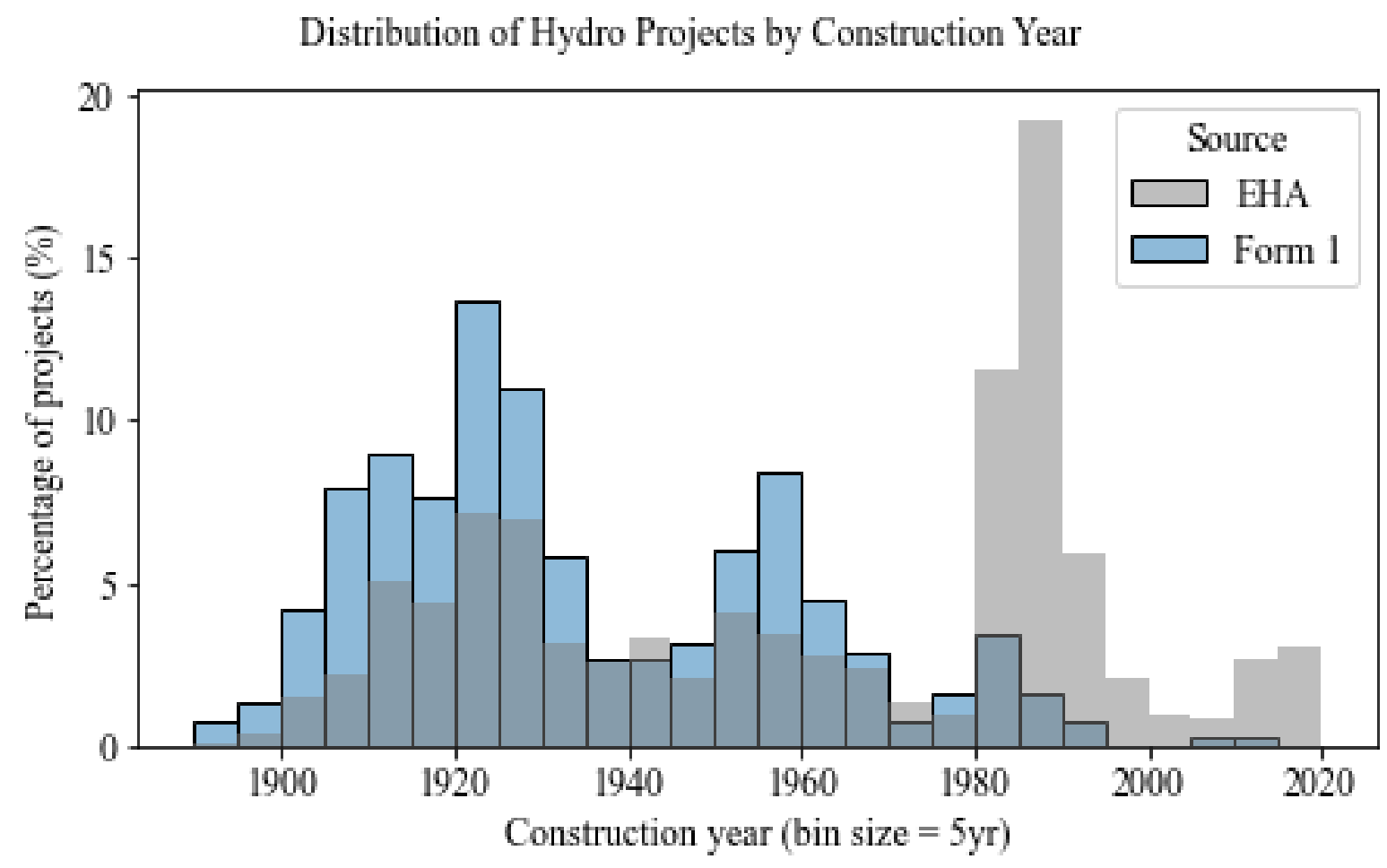

Figure 5. Histogram of Form 1 and EHA hydropower projects by construction year.

Operating mode provides a broad description of the role of a plant in meeting electricity demand on its connected power grid. For example, peaking plants are necessary for meeting loads during high electricity demand parts of the day. Hydropower is an attractive option for meeting peak loads because of the fast response time needed during these periods. However, peaking plants also tend to be used less often precisely because of the need to be available during these periods. Therefore, there are likely differences in O\&M costs between peaking and run of river (ROR) plants. Figure 6 shows that the Form 1 projects skew slightly towards peaking projects and away from ROR projects compared with the EHA data. The larger proportion of ROR plants in the EHA data versus the Form 1 data reflects the large number of small hydropower plants not captured in the latter. Peaking plants tend to be larger because of increased storage needs, so this trend follows the overrepresentation of large plants in the Form 1 data. Even so, nearly $40 \%$ of the Form 1 data are ROR plants. 


\section{Hydro Projects by Operating Mode}

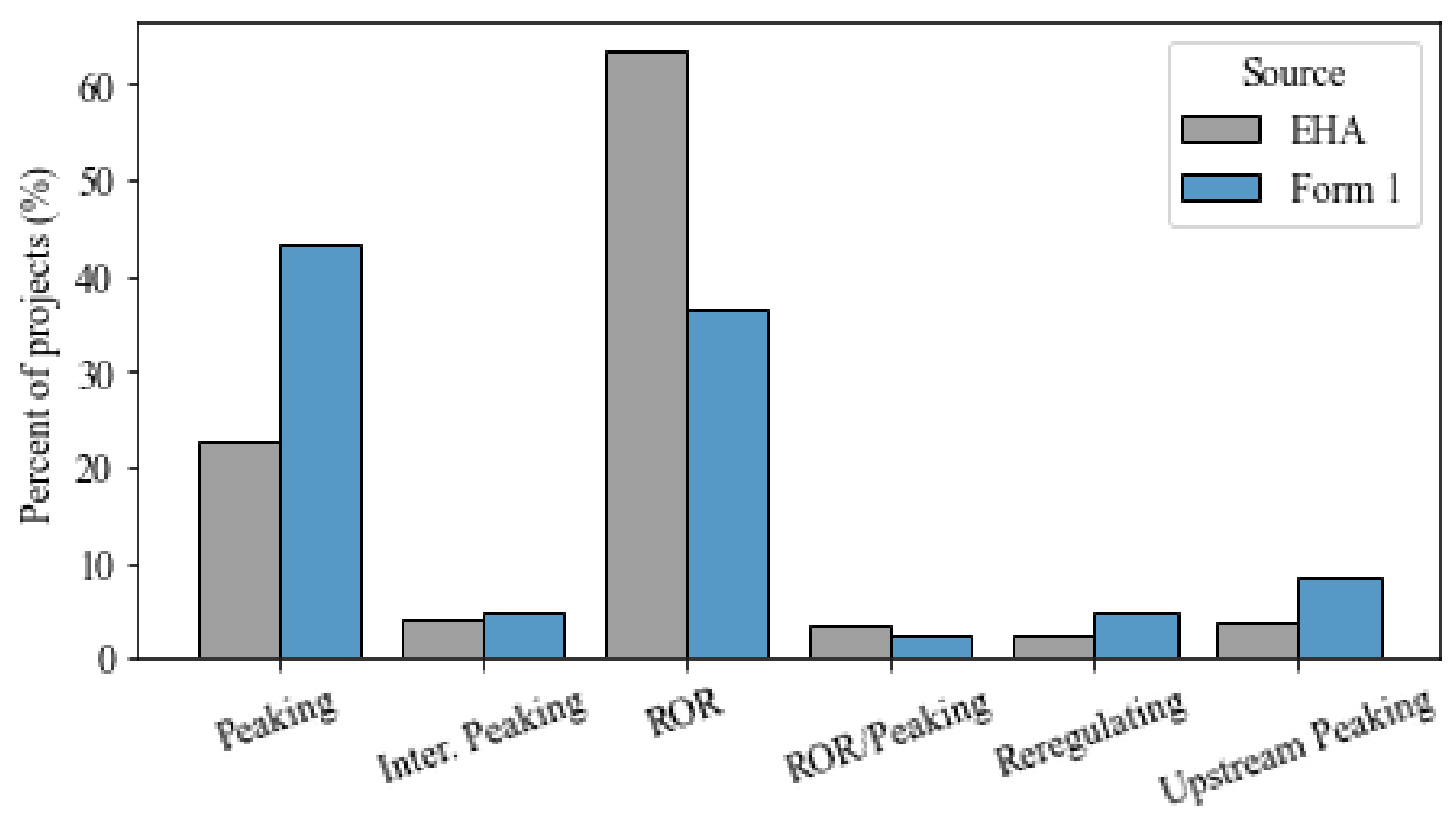

Figure 6. Histogram of Form 1 and EHA hydropower projects by operating mode.

\subsubsection{Operation Measures}

Figure 7 shows changes in the CWAA capacity factor by capacity class for hydropower facilities over time. Capacity factors were calculated by dividing the reported annual net generation by the maximum possible generation based on the nominal capacity for each entry. Notably, the capacity factor across all classes has ranged from highs of about $67 \%$ to as low as $25 \%$ but has increased since 2015 . Although the average hydropower capacity factors were highly variable over time, most were generally above $30 \%$ across years. The variation in capacity factors over time is driven by water resource conditions, electricity market changes, outages, etc., as well as changes in the cohort of plants reported in the Form 1 data.

The average number of employees is reported in the Large Hydro and Pumped Storage Hydro schedules of the Form 1 data. Figure 8 shows the CWAA number of employees for Large Hydro projects over time. The averages in Figure 8 exclude any plant that reported having zero employees because there was no distinction between plants with no employees and plants that did not report. Overall, the average number of employees has decreased over the report period, potentially resulting from increased automation practices. As expected, the average number of employees is smaller for the smaller capacity classes, with a range of 5 to 22 across all classes. The decline in the average number of employees is most dramatic for the largest >100 MW class, declining by nearly 50\% in 2020 from about 22 in 1994. 


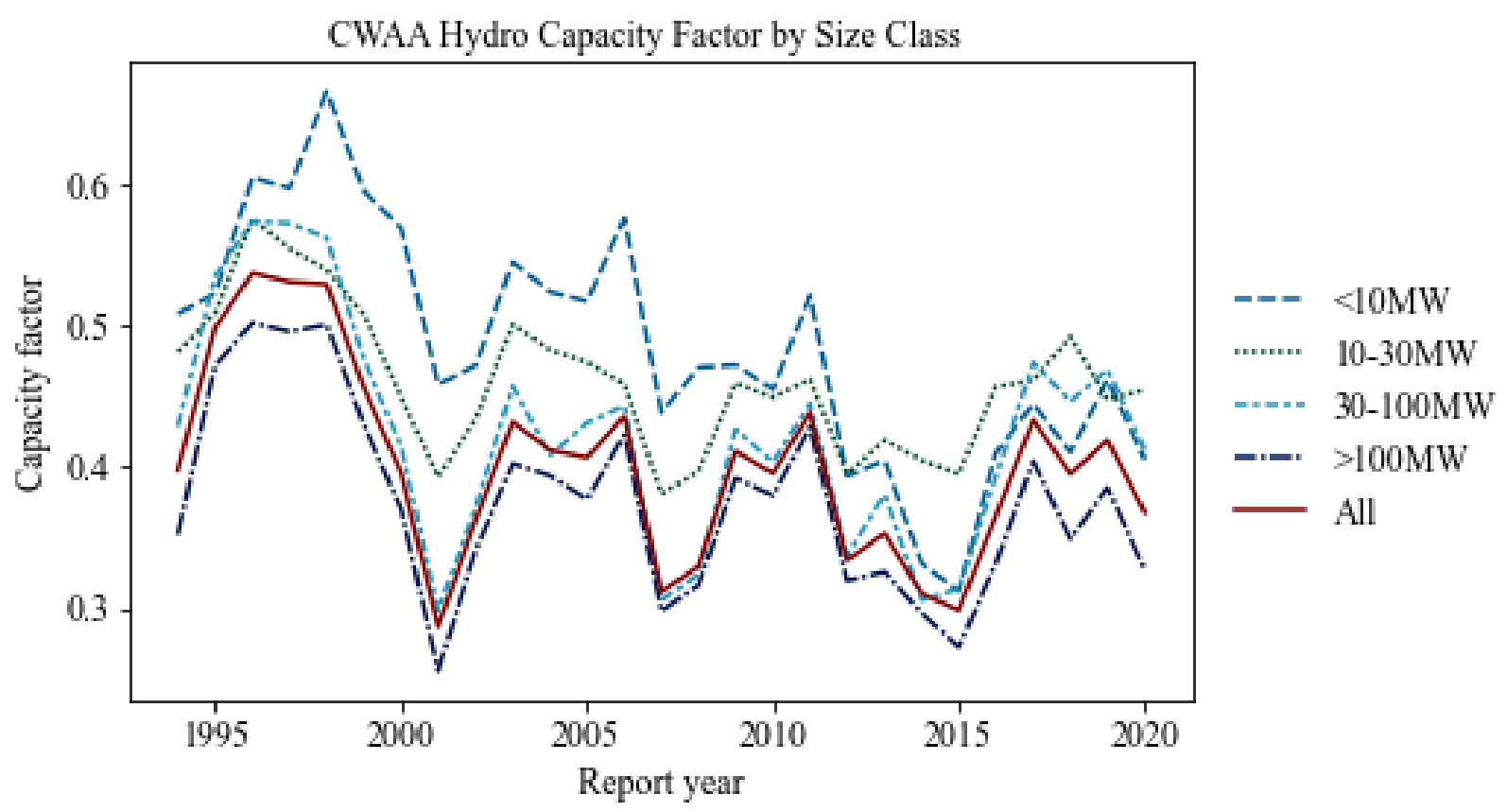

Figure 7. Capacity factor time series for hydropower plants by size class.

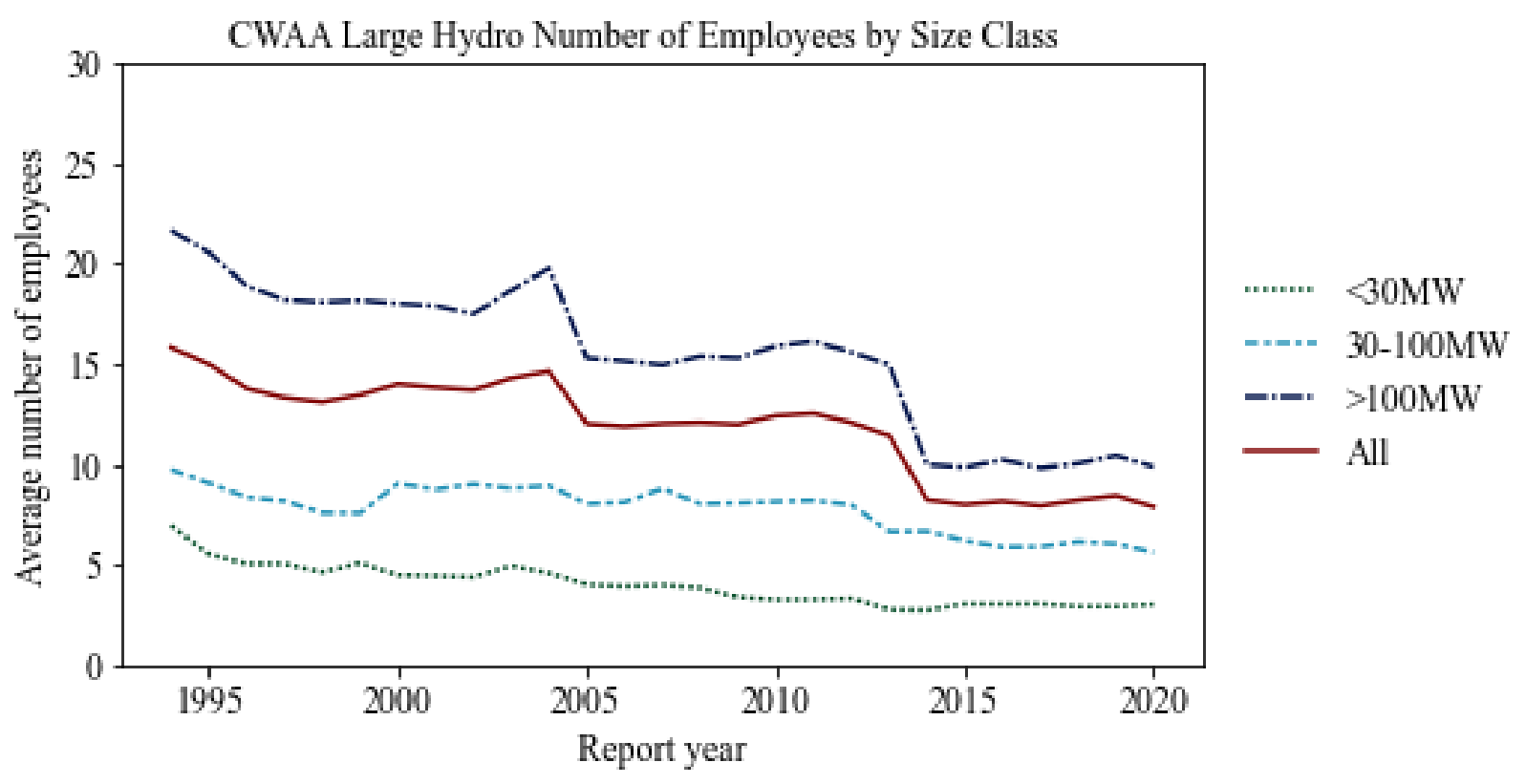

Figure 8. Capacity-weighted annual average number of employees for Large Hydro projects over the report period (1994-2020) for three size classes.

\subsubsection{Capital Costs}

This section presents capital cost data for conventional hydropower projects reported in the Small Plants and Large Hydro schedules of the Form 1 data. Note that the capital cost accounts are reported as the running sum of book costs for plant assets, unadjusted for inflation. Since Figure 5 shows that most plants in the Form 1 data were originally built before 1994, and dates of new asset purchases are not recorded, the costs cannot be fully adjusted to a common dollar year. As previously discussed, the reported Form 1 
capital costs for each year were escalated to the 2020 dollar-year in this report, but these are likely to underestimate adjusted capital costs, particularly those incurred in the distant past. Additionally, Small Plants are required to report only total capital and operating costs, whereas Large Hydro projects also report cost breakdowns by components. Thus, when total costs are presented in this report, the data is a combination of Small Plants and Large Hydro plants categorized into the following size classes based on the installed capacity for the latest year: $<10 \mathrm{MW}, 10-30 \mathrm{MW}, 30-100 \mathrm{MW}$, and >100 MW. When component costs are discussed in this report, which include data only from the Large Hydro schedule, the following classes are used: $<30 \mathrm{MW}, 30-100 \mathrm{MW}$, and $>100 \mathrm{MW}$. Cost per kilowatt $(\$ / \mathrm{kW})$, calculated by dividing total costs (or cost components) by the installed nameplate capacity, is used in this report to better compare costs for different sized plants. Hydropower plants often benefit from economies of scale across capacity and hydraulic head, so larger plants tend to cost less per kilowatt [2].

Figure 9 illustrates the capital cost distributions for each plant's latest report year (2020) in the Form 1 data. Plants with reported costs of $\$ 10,000 / \mathrm{kW}$ or greater in $\$ 2020$ are excluded from Figure 9 . Although the distribution of the capital costs would be affected by the inability to accurately adjust the data to a common dollar year, distinct patterns can still be seen in the data. The capital cost data is skewed to the right for all capacity-class data plots, leading to mean costs that are higher than the median. In addition, the role of economies of scale can be seen in the much lower capital costs for larger hydropower capacity classes than smaller ones. The mean costs for $<10 \mathrm{MW}$ and 10-30 MW plants are about two times higher than those for the two larger capacity classes. Smaller projects also exhibited larger variability in capital costs.

Figure 10 shows the capacity-weighted shares of each capital cost component by capacity class for the Large Hydro schedule data. The cost components within each account are described in Appendix B based on the "Uniform System of Accounts." The distribution of costs across the five accounts is relatively similar across the capacity classes, with facilities and equipment representing approximately $80 \%$ of total capital costs. The facilities account comprises the initial costs for the reservoirs, dams, waterways, and other facilities used for "impounding, collecting, storage, diversion, regulation, and delivery of water used primarily for generating electricity." These facilities account for $38.7 \%$ to $44.5 \%$ of costs across all capacity groups, with an average of about $39 \%$ for all plants. The equipment category as reported in the Form 1 data appears to be a combination of several accounts (333-335), which include water wheels, turbines, generators, accessory electric equipment, and miscellaneous power plant equipment accounting for $38 \%$ to $43 \%$ of the costs, with an average of about $42 \%$ for all plants. Structures (and improvements) make up most of the remaining cost with the land (and land rights) and roads components between $1 \%$ and $4 \%$.

Figure 11 shows the trend in reported capital costs over time after inflation adjustment. The $>100 \mathrm{MW}$ size class shows a relatively stable capital cost trend over the 26 years. The other size classes show a gradual increase in capital costs. The increases in capital costs are more pronounced for the $<10 \mathrm{MW}$ and 10-30 MW capacity classes. These cost increases might reflect increases in the cost of asset additions or increases in the cost of retirement units (e.g., turbines and generators), as well as the changes in the composition of plants reported in the Form 1 data. 

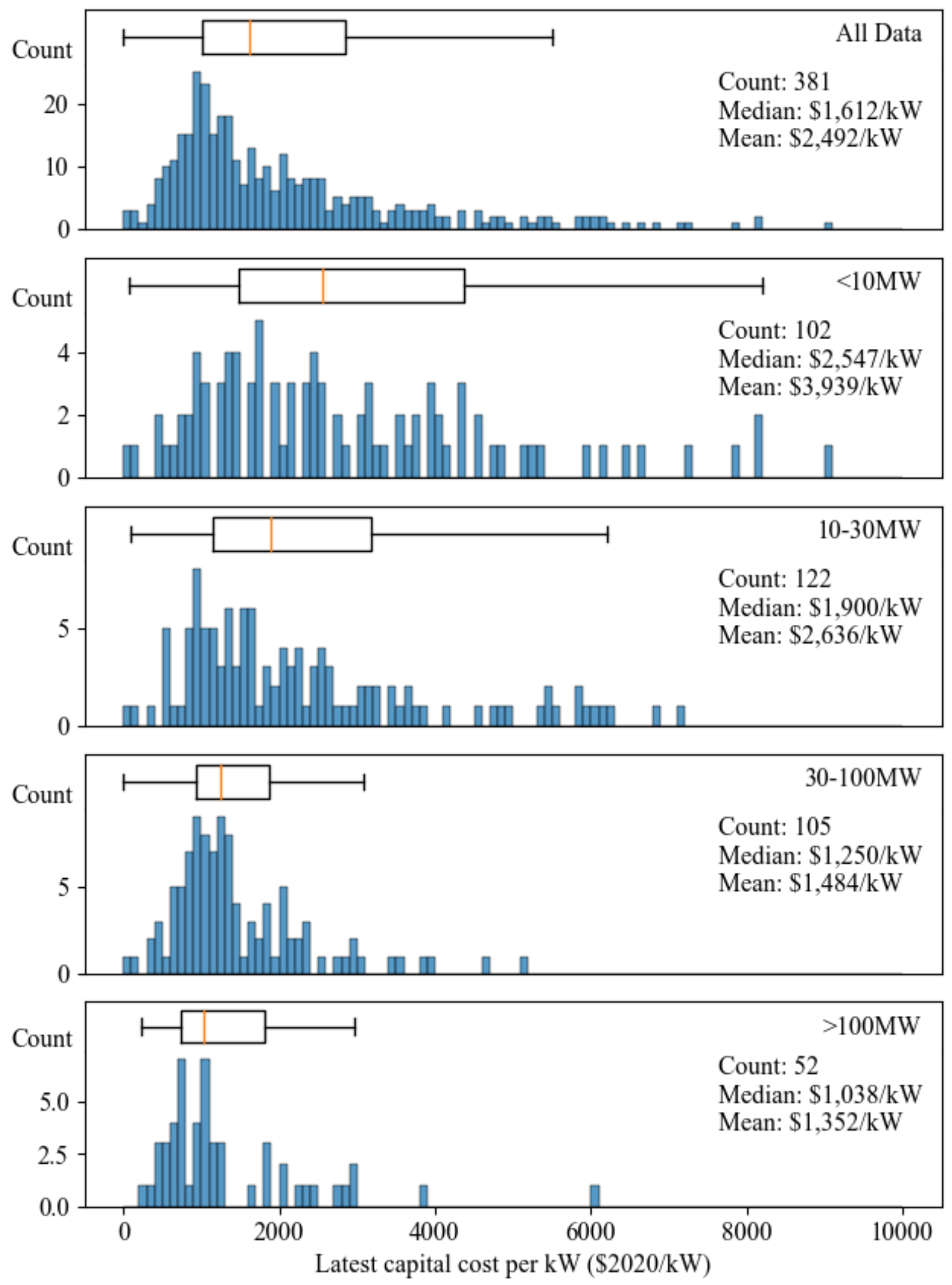

Figure 9. Capital costs per kilowatt for the Small Plant and Large Hydro schedules by capacity class for latest report year. Plants with costs greater than $\$ 10,000 / \mathrm{kW}$ are not included (13 plants). (Note: Form 1 capital cost data are running asset book values.) 

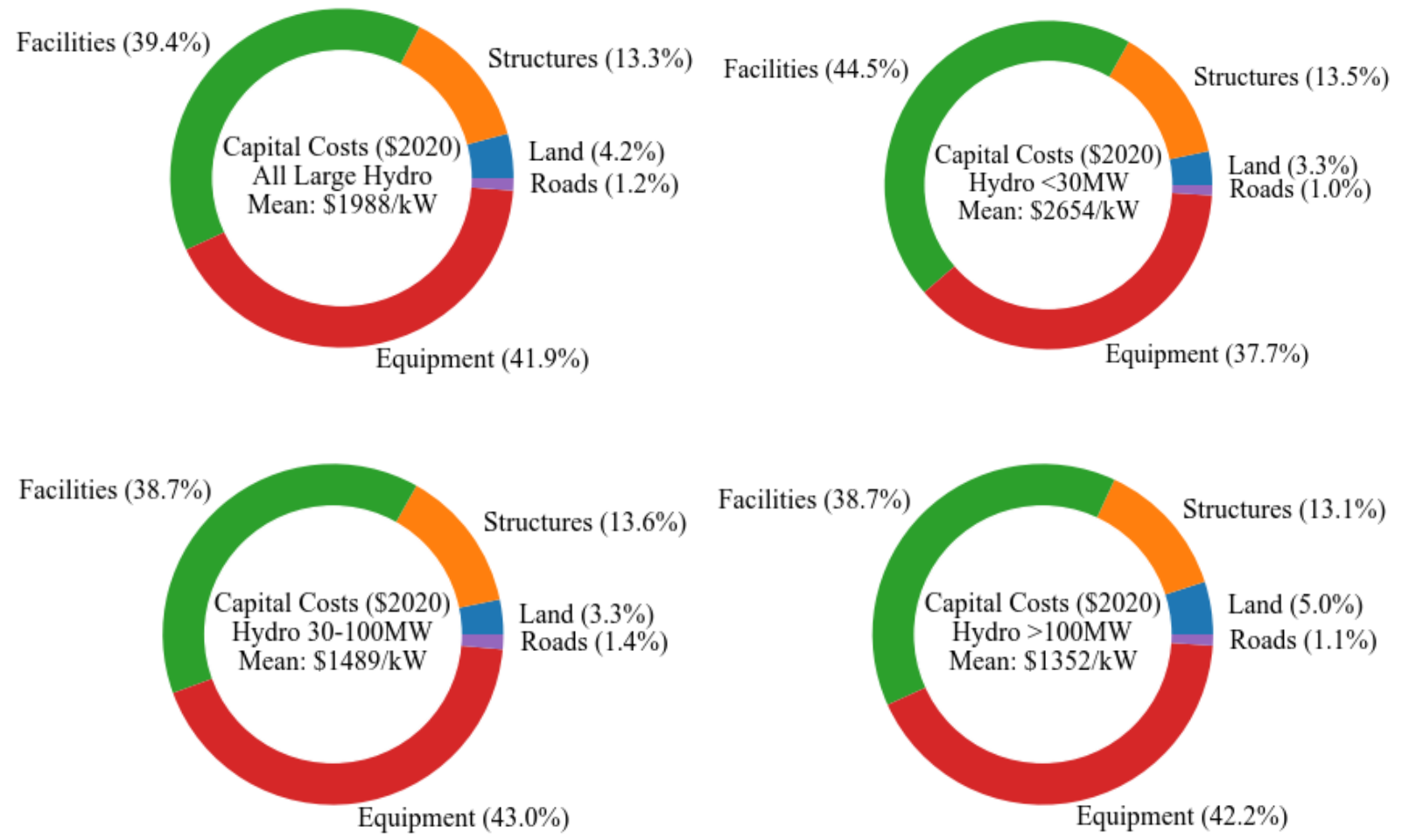

Figure 10. Capital cost breakdowns by components for Large Hydro plants for latest report year. (Note: Form 1 capital cost data are running asset book values.)

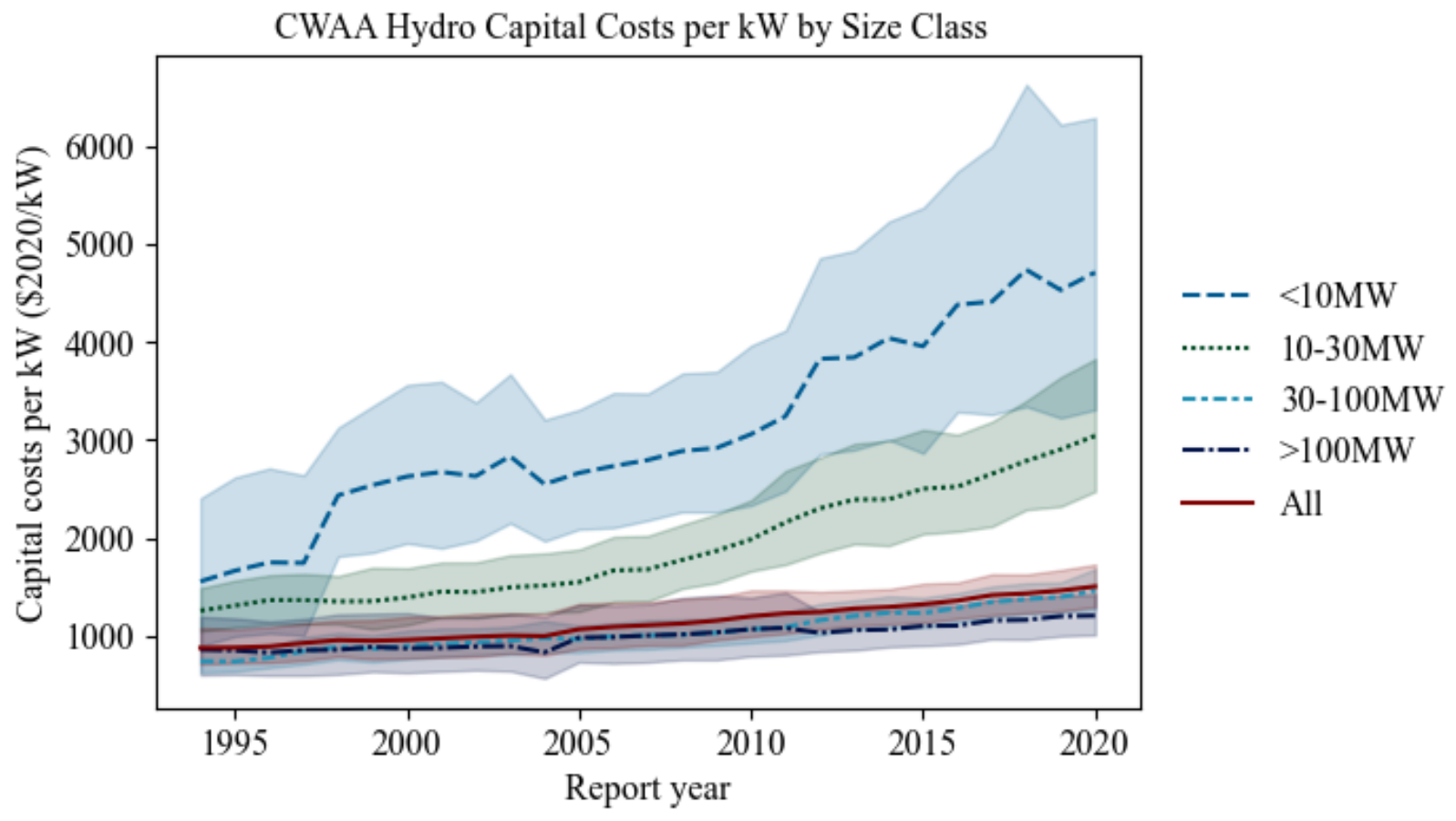

Figure 11. Capacity-weighted annual average capital costs for the Small Plant and Large Hydro schedules over reporting years 1994-2020. Shaded regions represent the 95\% confidence interval. (Note: Form 1 capital cost data are running asset book values.) 


\subsubsection{Operation and Maintenance Costs}

This section presents the reported O\&M cost data for conventional hydropower projects, referred to as "expenses" in the Form 1 data. Figure 12 shows the distribution of O\&M costs $(\$ / \mathrm{kW})$ for each size class. All entries with valid total O\&M cost information are included and escalated to $\$ 2020$. The distribution of O\&M costs, like those for capital costs, is skewed to the right. The median and mean O\&M costs over all plants are $\$ 46 / \mathrm{kW}$ and $\$ 71 / \mathrm{kW}$, respectively, with values much higher for the $<10 \mathrm{MW}$ class than the other capacity classes with a median of $\$ 126 / \mathrm{kW}$. Thus, as with the capital costs, there are economies of scale in hydropower O\&M costs.

Figure 13 shows the breakdown of the O\&M costs by components for the Large Hydro projects in the Form 1 data: operation costs are identified by the suffix "-O" and maintenance cost by the suffix "-M" (see Table 2 and Appendix B for the name descriptions). The distribution of costs among components is similar across capacity classes, except for the $<10 \mathrm{MW}$ class, where the hydraulic operation costs were negligible. Operation costs generally represented slightly more than half of total O\&M costs. The largest operation cost categories are miscellaneous, superv\&eng, electric, and hydraulic, each representing between $6 \%$ and $22 \%$ of total O\&M costs. The largest maintenance cost categories are electric, dams, and miscellaneous, each representing between $7 \%$ and $17 \%$ of total O\&M costs.

Figure 14 shows that $O \& M$ costs $(\$ / \mathrm{kW})$, adjusted for inflation, are relatively stable over the 26 years for the three largest capacity classes but have increased for the $<10 \mathrm{MW}$ class. Figure 15 shows the O\&M costs as a function of annual energy generation for each year and exhibits a similar pattern of higher and more variable costs for smaller projects. 

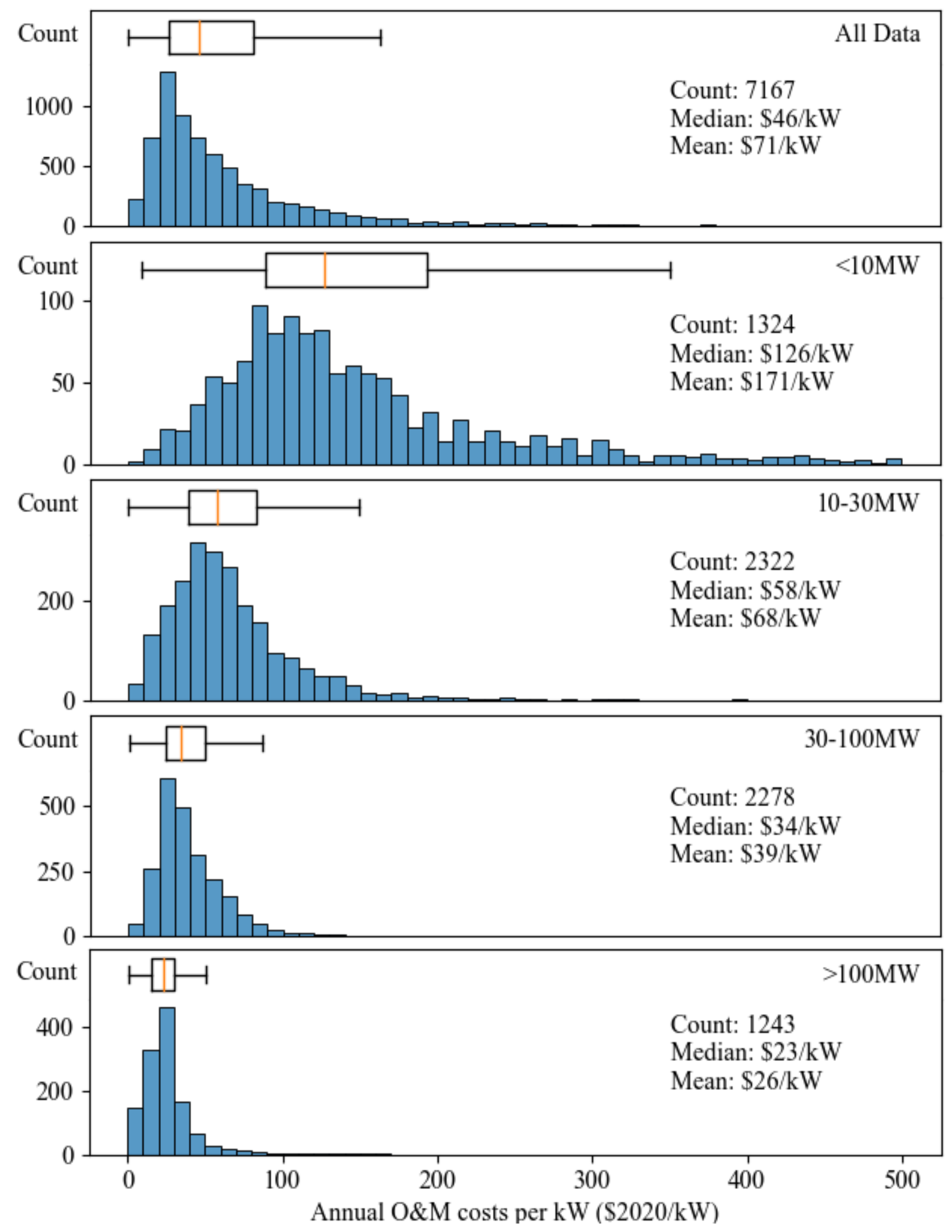

Figure 12. O\&M costs for the Small Plant and Large Hydro schedules by size class. Entries over $\$ 500 / \mathrm{kW}$ are excluded (64 entries). 

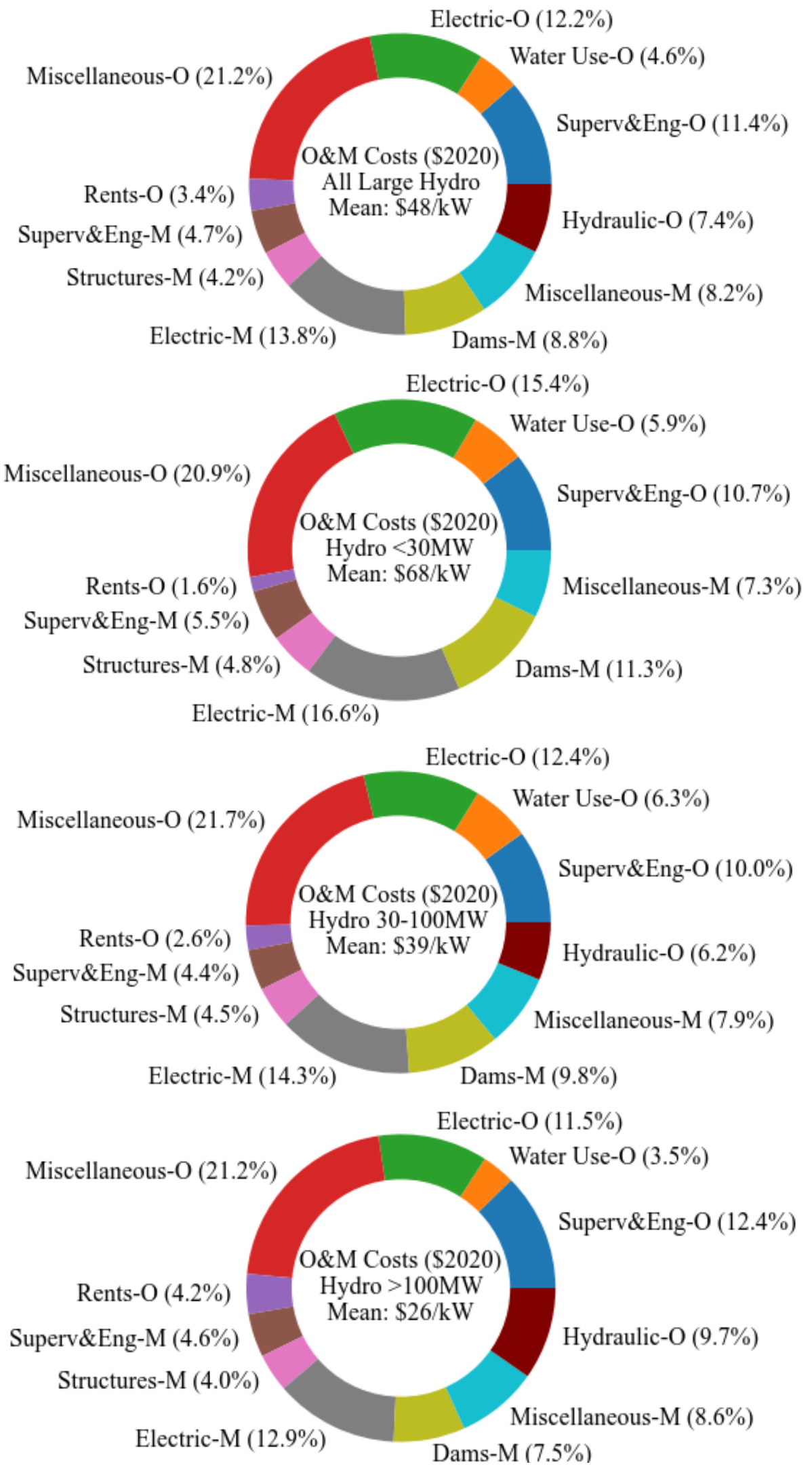

Figure 13. O\&M cost account breakdowns for Large Hydro plants. 


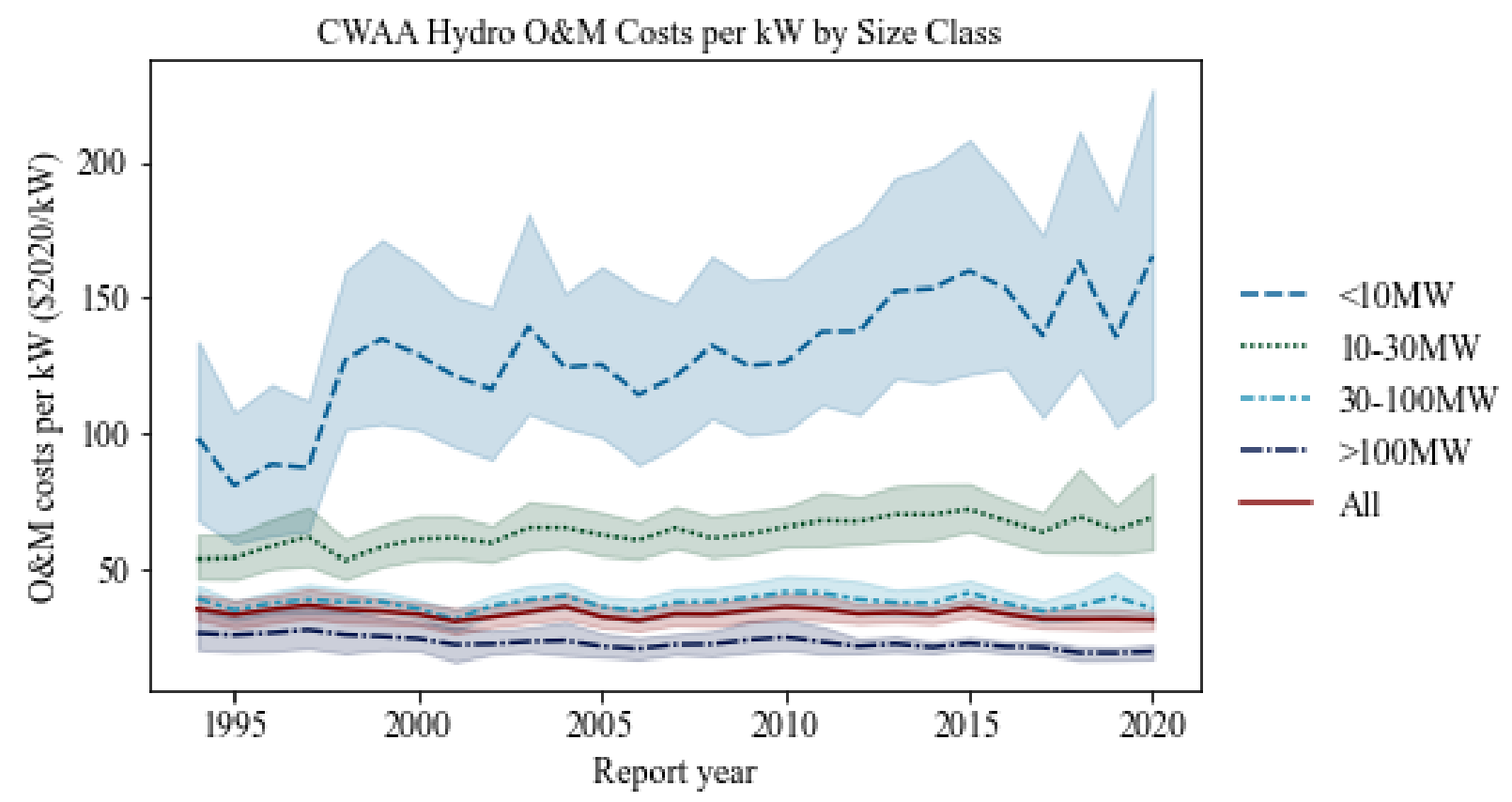

Figure 14. Average annual O\&M cost time series by size class for Small Plants and Large Hydro schedules. Shaded region represents the $95 \%$ confidence interval.

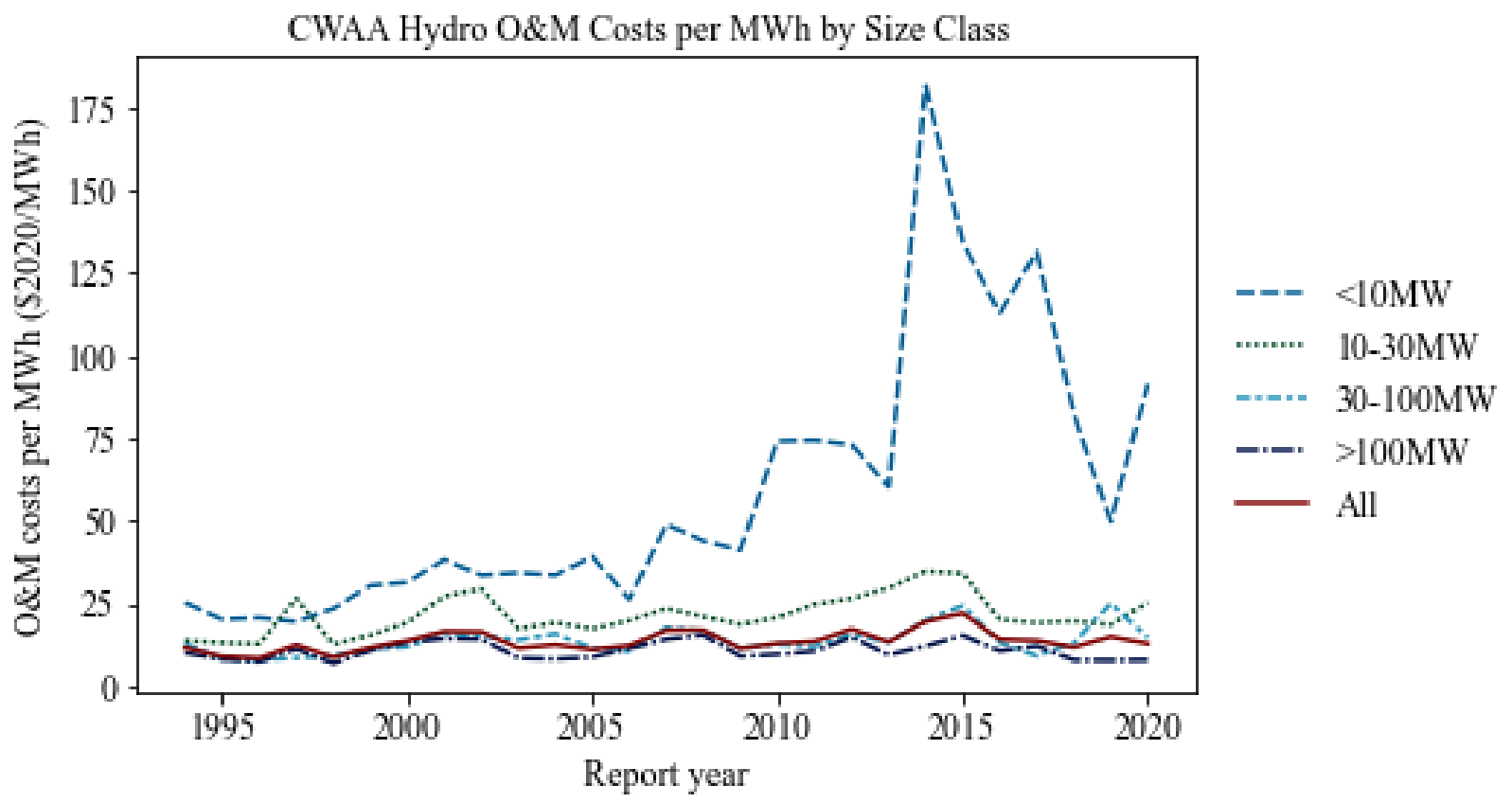

Figure 15. Capacity-weighted annual average O\&M costs per megawatt-hour for Form 1 hydropower plants by size class. 


\subsection{PUMPED STORAGE HYDROPOWER}

\subsubsection{Plant Characteristics}

The Form 1 database contains only 23 PSH plants, so the plants are not categorized by capacity class in this report. In comparison, there are 43 PSH plants in the EHA database. In some cases, plants have both conventional hydropower and pumped storage capabilities. For this section, any plants with pumped storage capabilities in EHA were included, but only the pumped storage capacity was plotted. Figure 16 shows the distribution of pumped storage capacities for the Form 1 and EHA data. Given that most PSH plants have capacities greater than $100 \mathrm{MW}$, the distribution of these plants in the Form 1 data is a good representation of the EHA population. Figure 17 shows that the most common dam types for PSH plants in Form 1 and EHA are rockfill, concrete, and earthen dam. However, the Form 1 data overrepresents rockfill dams and underrepresents concrete and earthen dams. Figure 18 shows a similar pattern where the construction years in the EHA database are well represented in the Form 1 database, but the latter omits plants built from 1940 to 1960 and since 2000.

\section{PSH Capacity Distribution by Size Class}

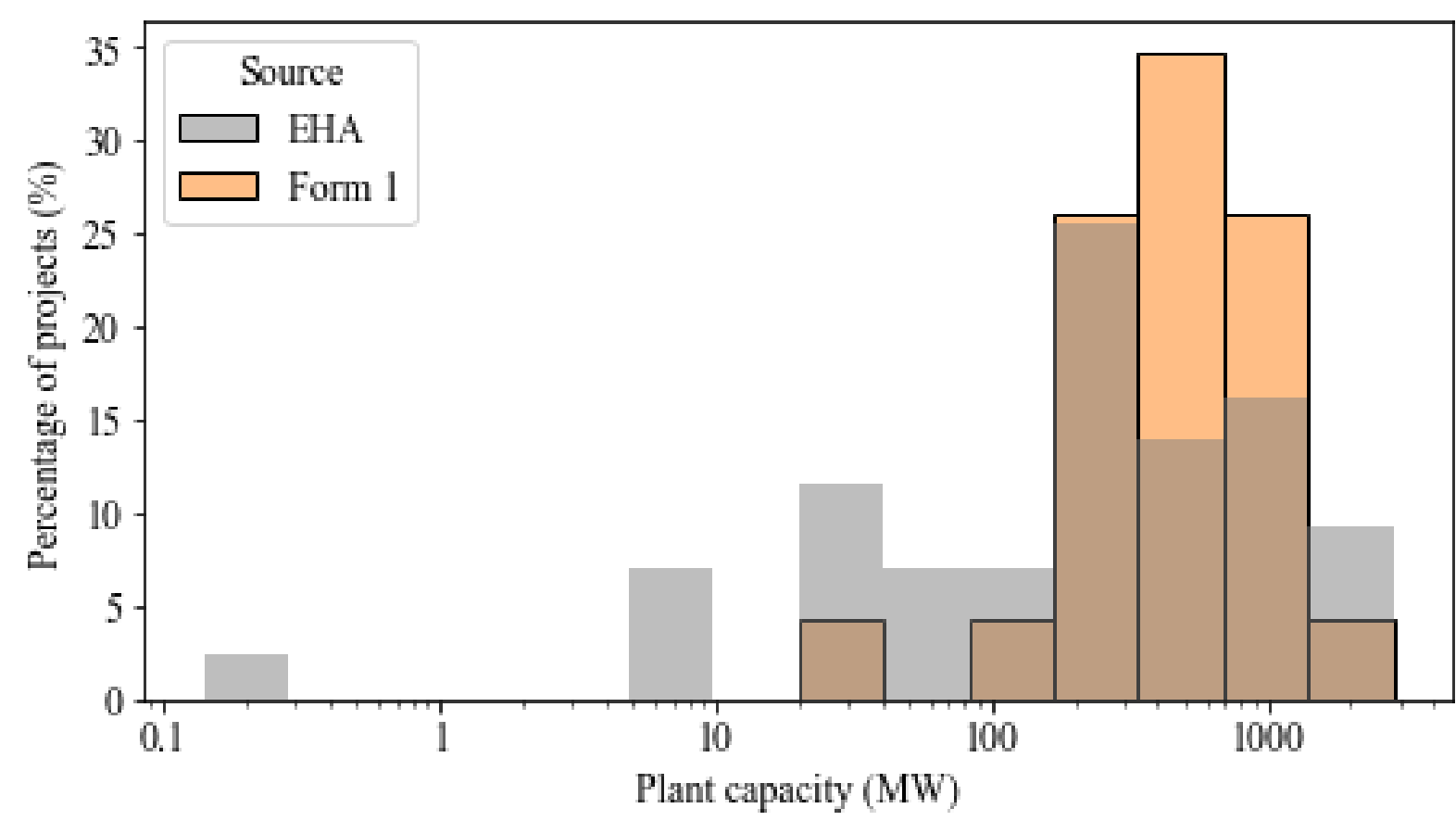

Figure 16. PSH plant installed capacity distribution comparison between the Form 1 database and the EHA database. 


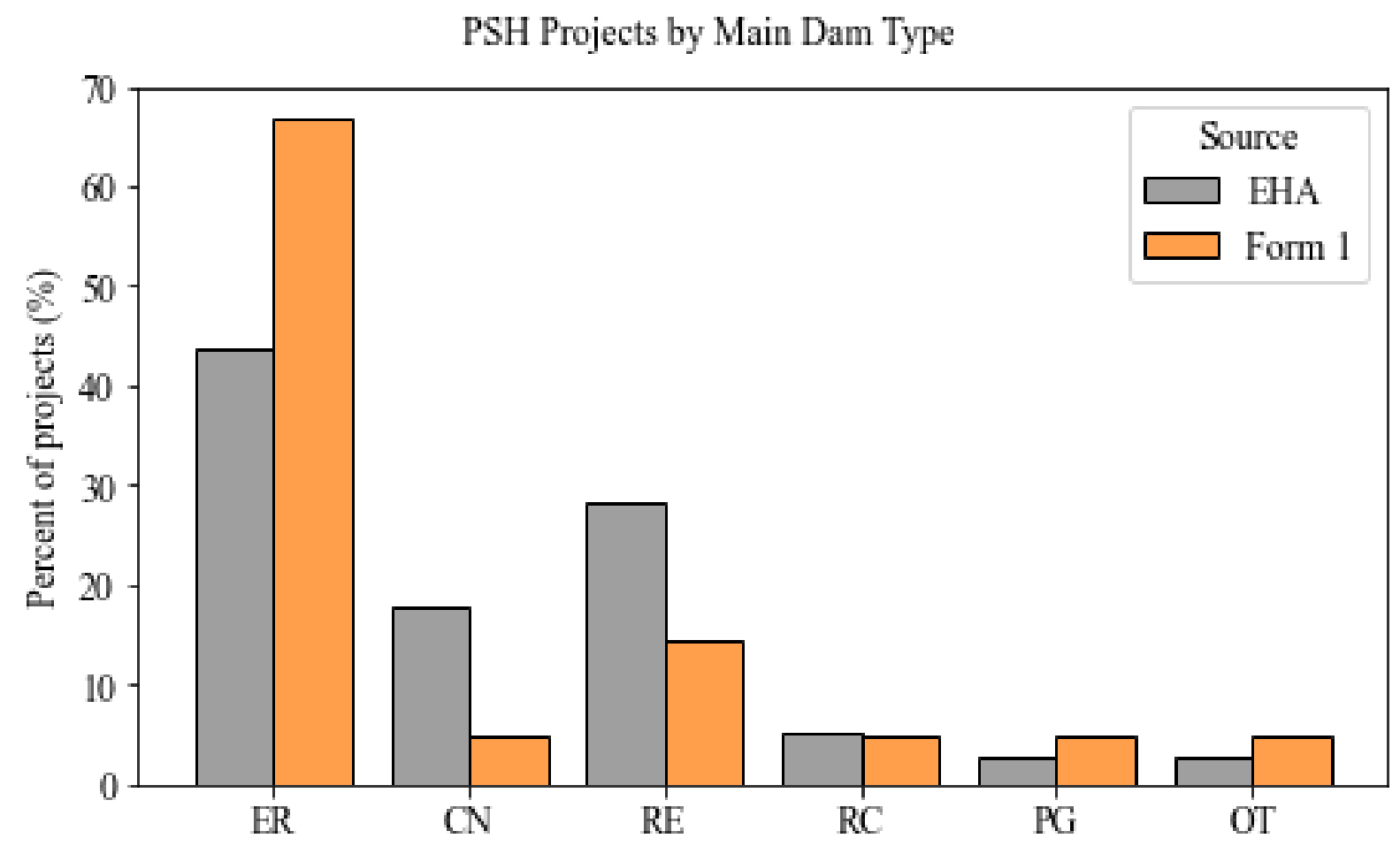

Figure 17. PSH plant main dam type distribution comparison between the Form 1 and EHA databases $(E R=$ rockfill, $\mathrm{CN}=$ concrete, $\mathrm{RC}=$ roller-compacted concrete, $\mathrm{RE}=$ earthen, $\mathrm{PG}=$ gravity, $\mathrm{OT}=$ others).

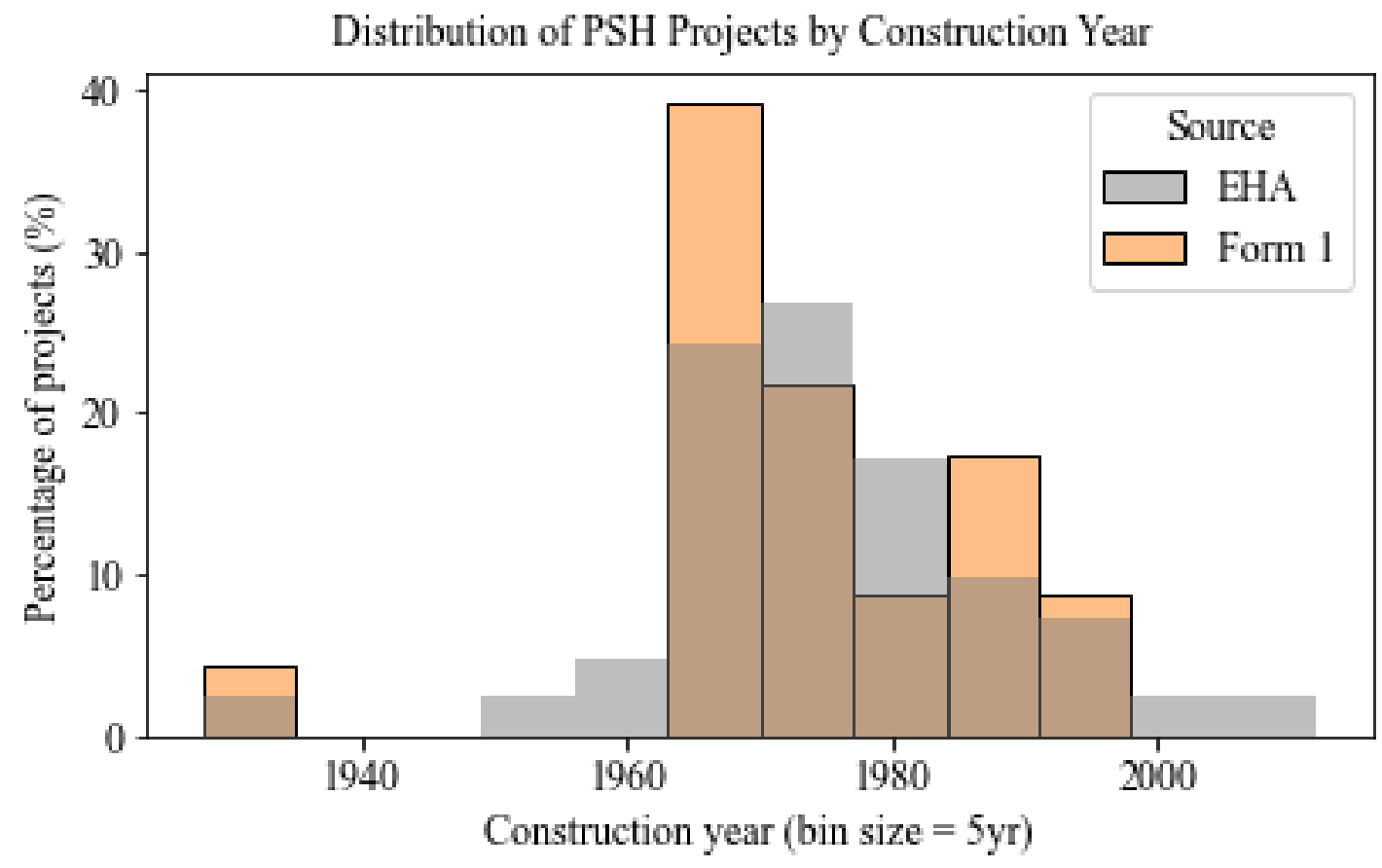

Figure 18. PSH plant construction year distribution comparison between the Form 1 and EHA data. 


\subsubsection{Operation Measures}

Figure 19 illustrates the CWAA capacity factor for all pumped storage plants in Form 1. These capacity factors relate the ratio of annual net generation to the maximum possible annual generation based on the nameplate capacity. The average capacity factor is relatively consistent over the report period ranging from $11 \%$ to $18 \%$, with recent capacity factors around $12 \%$. Although the capacity factor estimates are relatively low, this accounts only for the generation operation of the PSH plant. With pumping operations, the capacity factor would be about double the generation estimates, falling in the middle range of capacity factor estimates for conventional hydropower in Figure 7. Since a PSH plant provides energy storage services and does not operate continuously, the capacity factor would be generally lower than a similarly sized conventional hydropower plant. The CWAA number of employees data shown in Figure 20 varies from 10 to 35. The average number of employees closely follows the reported PSH capacity changes in Figure 2, indicating the influence of changes in plant characteristics in the Form 1 data over time.

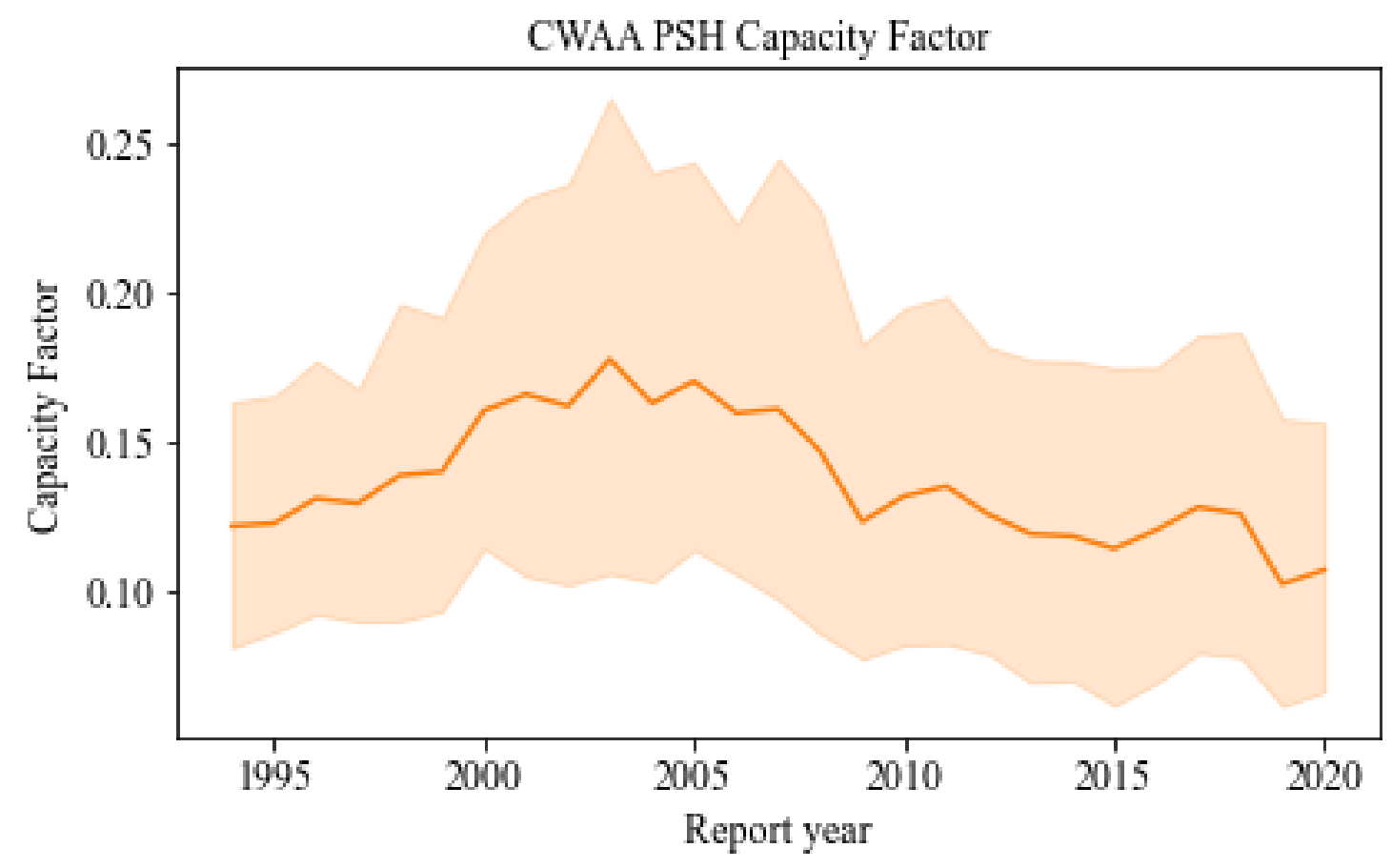

Figure 19. Capacity-weighted annual average capacity factor for PSH plants. Shaded region represents the $95 \%$ confidence interval. 


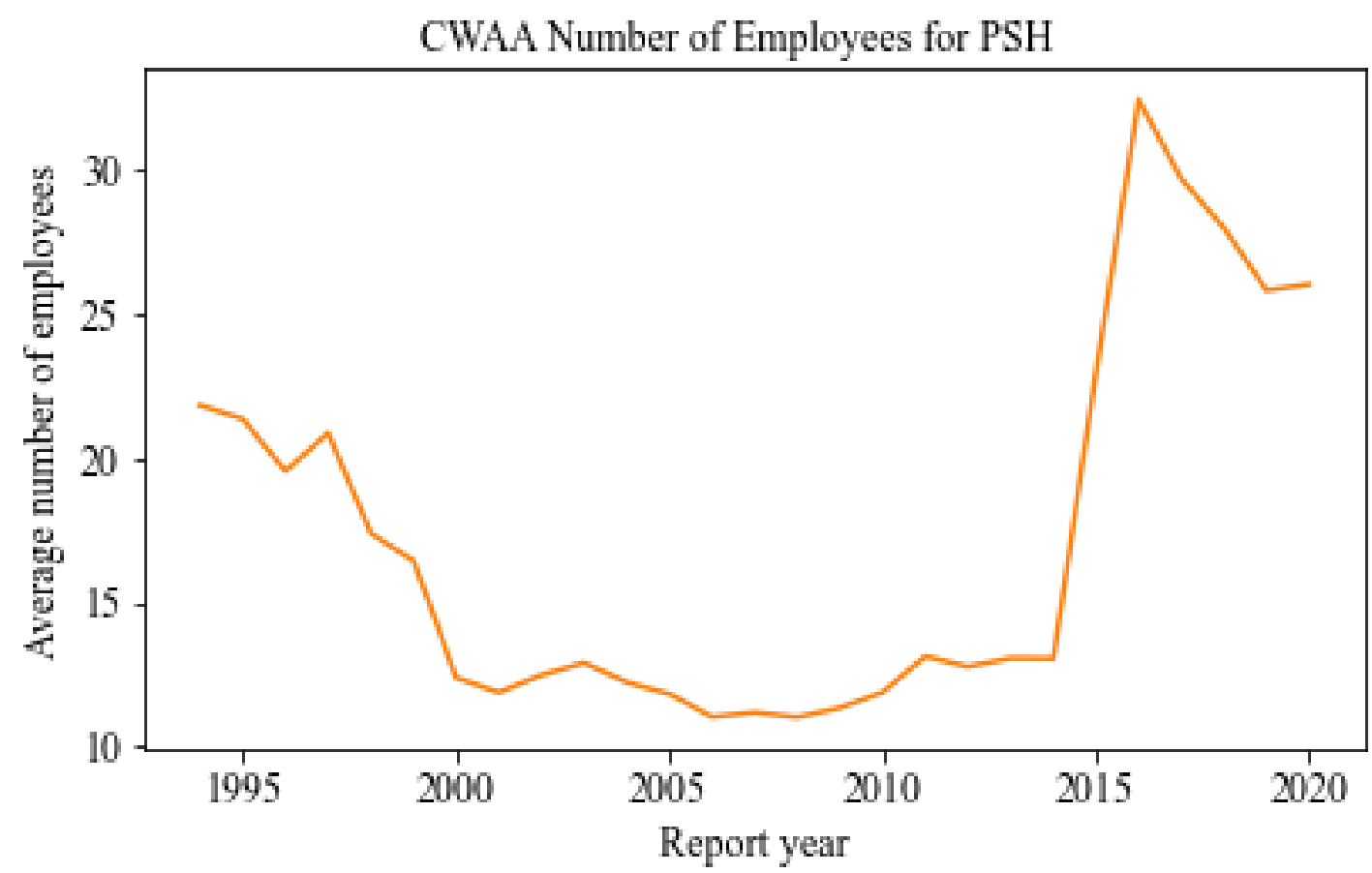

Figure 20. Capacity-weighted annual average number of employees for PSH plants.

\subsubsection{Capital Costs}

This section presents the capital costs for the PSH plants in the Form 1 database. Figure 21 shows the distribution of capital costs for the Form 1 PSH plants. At about $\$ 898 / \mathrm{kW}$, the average capital cost is less than any conventional hydropower size class (the conventional $>100 \mathrm{MW}$ class averaged $\$ 1352 / \mathrm{kW}$ ). This follows from the generally larger capacities of PSH plants with an average capacity of $580 \mathrm{MW}$ compared with an average capacity of $60 \mathrm{MW}$ for conventional hydropower in the Form 1 data. The cost difference could also be the result of different plant structure and equipment needs for a PSH versus a conventional plant of the same capacity.

Figure 22 shows the average breakdown of PSH capital cost into the components. The three largest accounts, representing about $86 \%$ of all costs, are wheels (water wheels, turbines, and generators) with about $32 \%$, facilities (reservoirs, dams, and waterways) with about $40 \%$, and structures (structures and improvements) with about 14\%. The electric cost component in Figure 22 is for auxiliary generation and other equipment; the PSH turbine-generator package costs are included in the wheels component. Figure 23 shows stable PSH capital costs per kilowatt over time. However, most of the PSH plants in the Form 1 database were built between 1960 and 1980, so the observed trend might not reflect modern costs for new sites, designs, or innovations. 
PSH Capital Costs

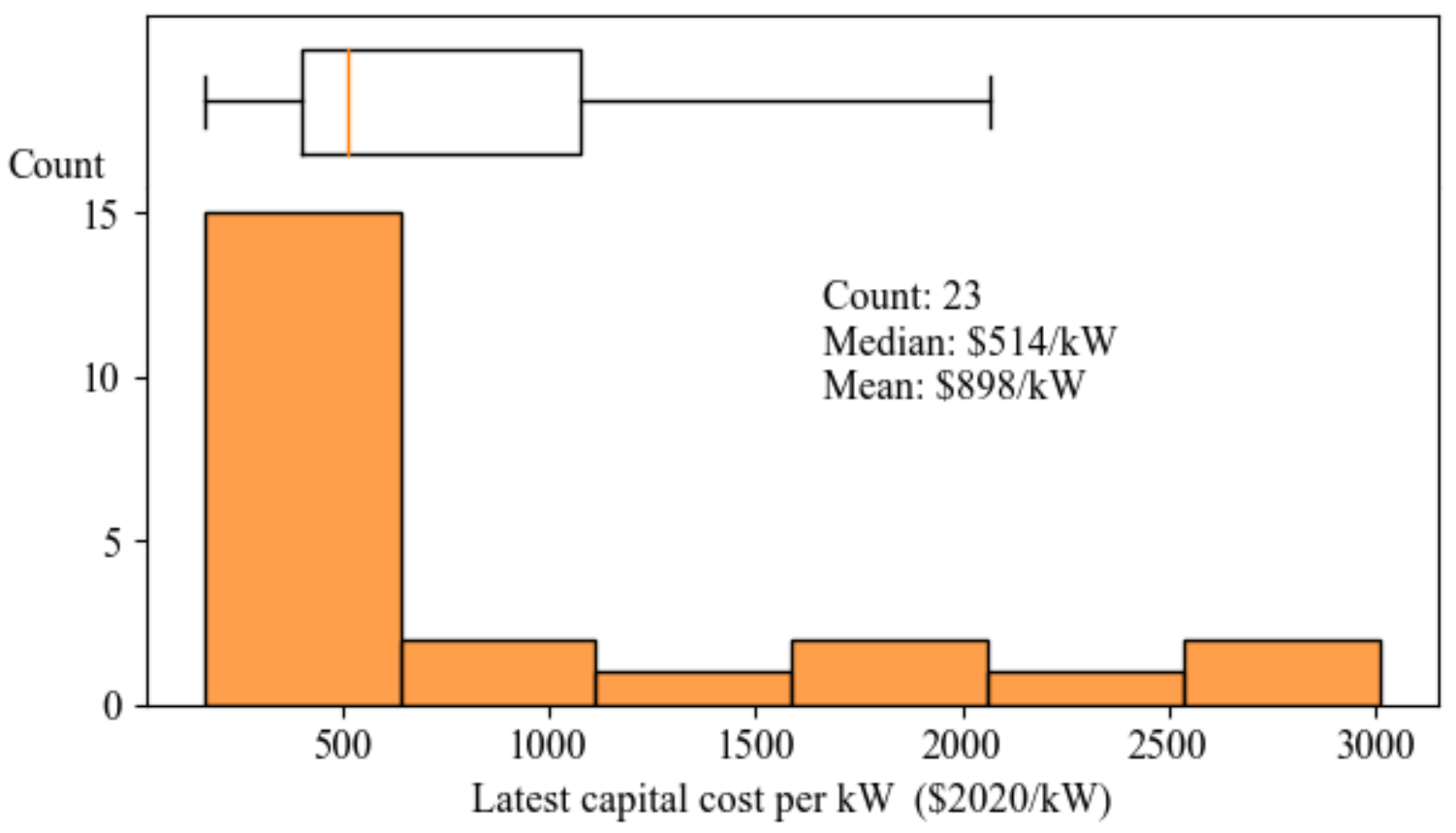

Figure 21. PSH plant latest capital cost distribution from the Form 1 data. (Note: Form 1 capital cost data are running asset book values.)

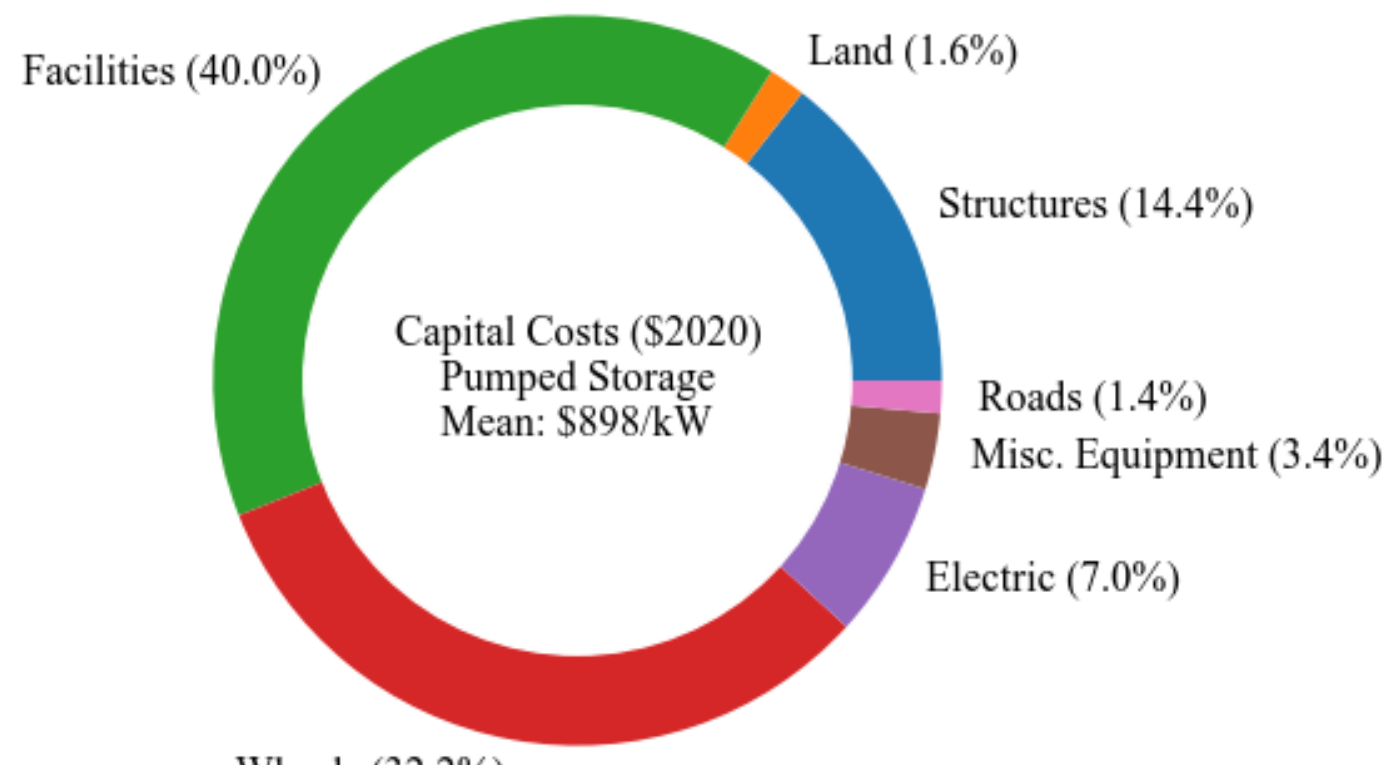

Wheels $(32.2 \%)$

Figure 22. Breakdown of Form 1 capital cost accounts for the PSH plants. (Note: Form 1 capital cost data are running asset book values.) 


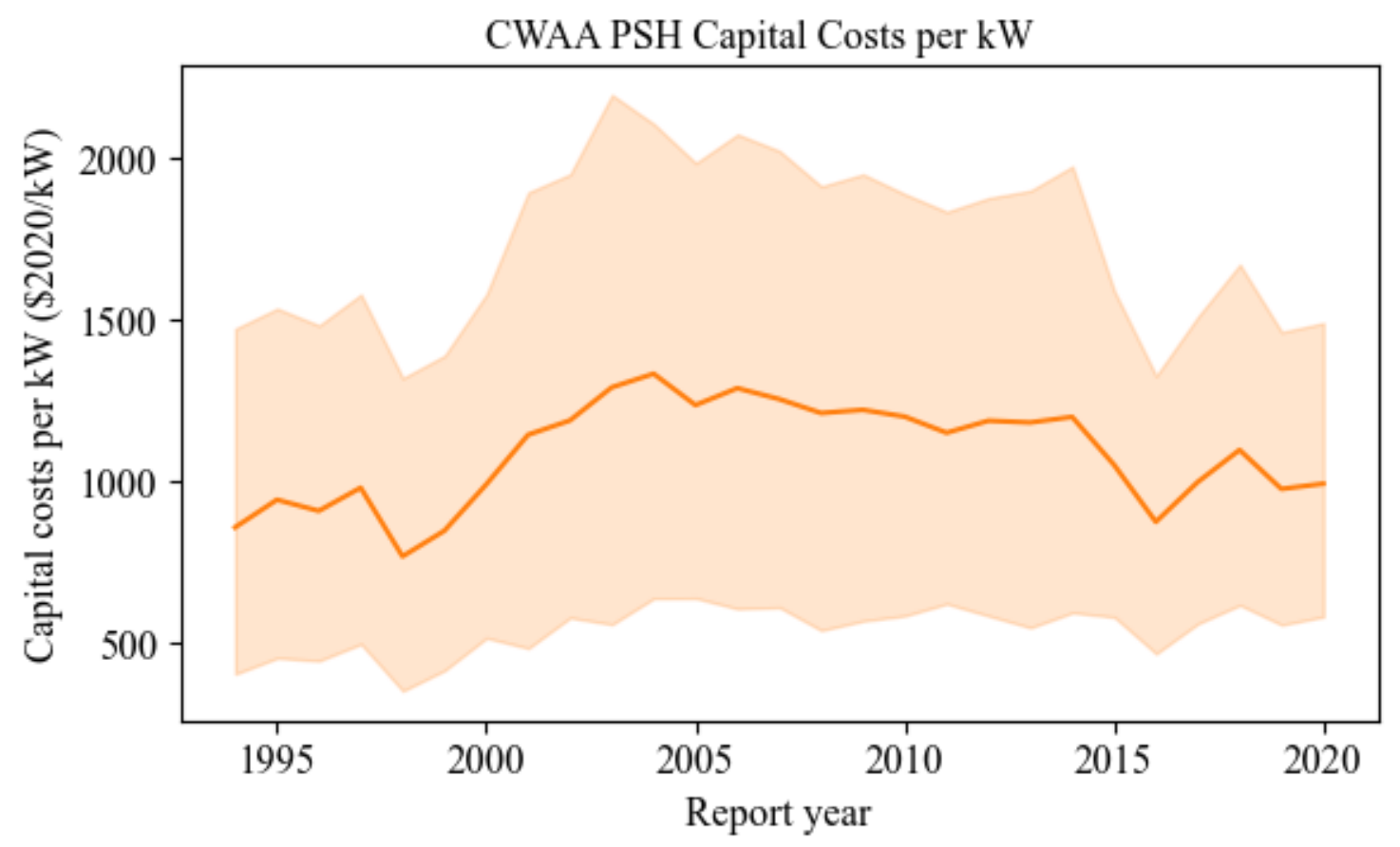

Figure 23. Time series of Form 1 PSH plant average capital cost per kilowatt. Shaded region represents the 95\% confidence interval. (Note: Form 1 capital cost data are running asset book values.)

\subsubsection{Operation and Maintenance Costs}

Pumped storage plants have similar O\&M cost components to hydropower projects but with the additional energy costs for pumping water and related maintenance activities. Figure 24 shows the distribution of O\&M costs for the PSH plants in the Form 1 database in $\$ / \mathrm{kW}$ and $\$ / \mathrm{MWh}$. The mean cost in $\$ / \mathrm{kW}$ for PSH plants is higher, but the median is lower than for the $>100 \mathrm{MW}$ class for conventional hydropower plants, indicating that the PSH distribution is more skewed to the right. A similar observation can also be made for O\&M costs in $\$ / M W h$.

Figure 25 shows the breakdown of average PSH O\&M costs by cost components. Operation costs (with "O" suffix in the name) account for more than $60 \%$, with pumping (the cost of energy required to pump water) at about $24 \%$, followed by miscellaneous power-related expenses at about $20 \%$, electric at about $7.6 \%$, and superv\&eng at about $7 \%$ of total O\&M costs. Maintenance of the electric plant is the largest maintenance expense at about $20 \%$ of total O\&M costs, while the other maintenance expenses are more evenly divided among the components, with most between 3\% and 7\% of total O\&M costs. Figure 26 shows that O\&M costs for PSH fluctuated over the 1994 to 2020 period, showing a slow but decreasing pattern since 2008 . 

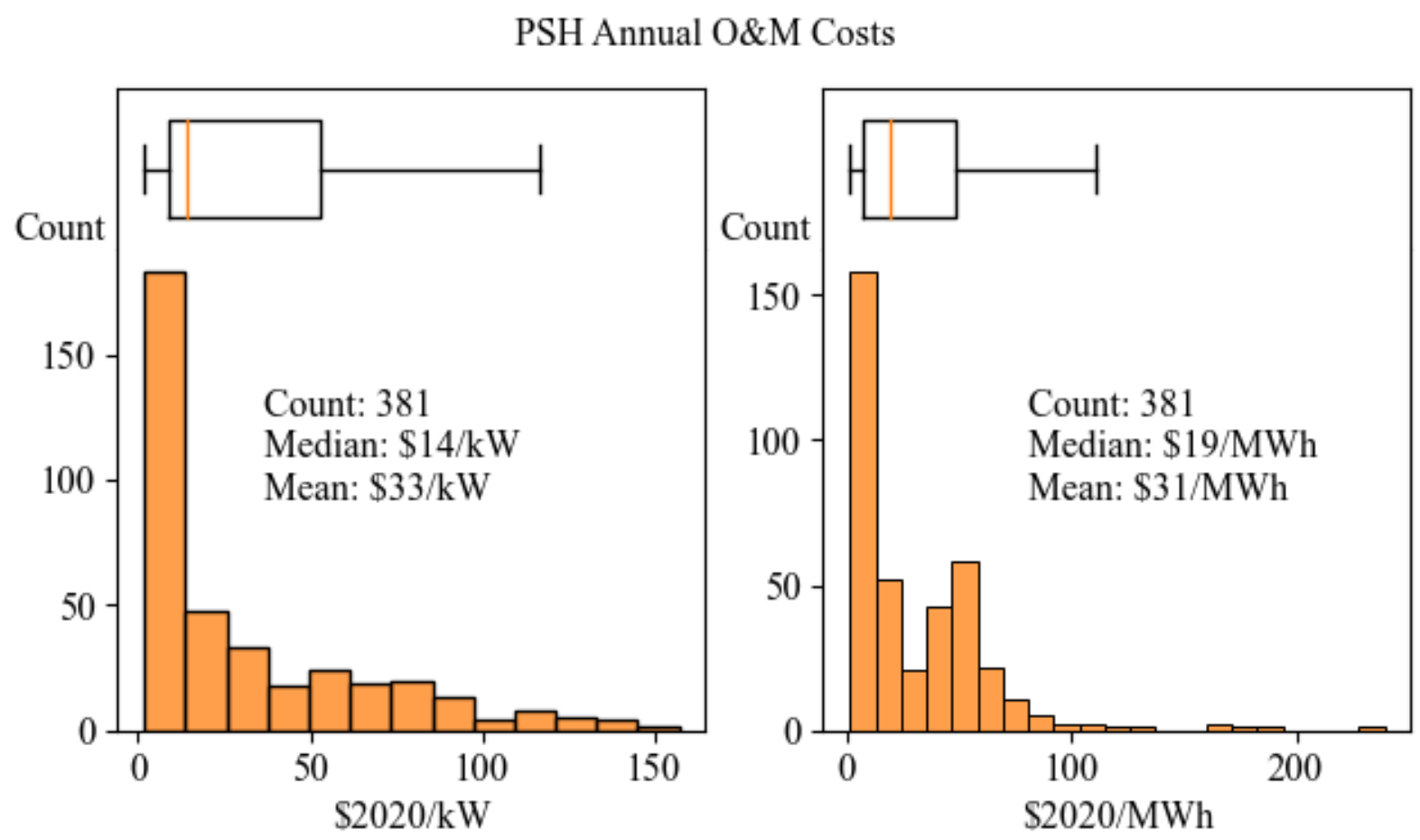

Figure 24. Annual O\&M costs for PSH plants.

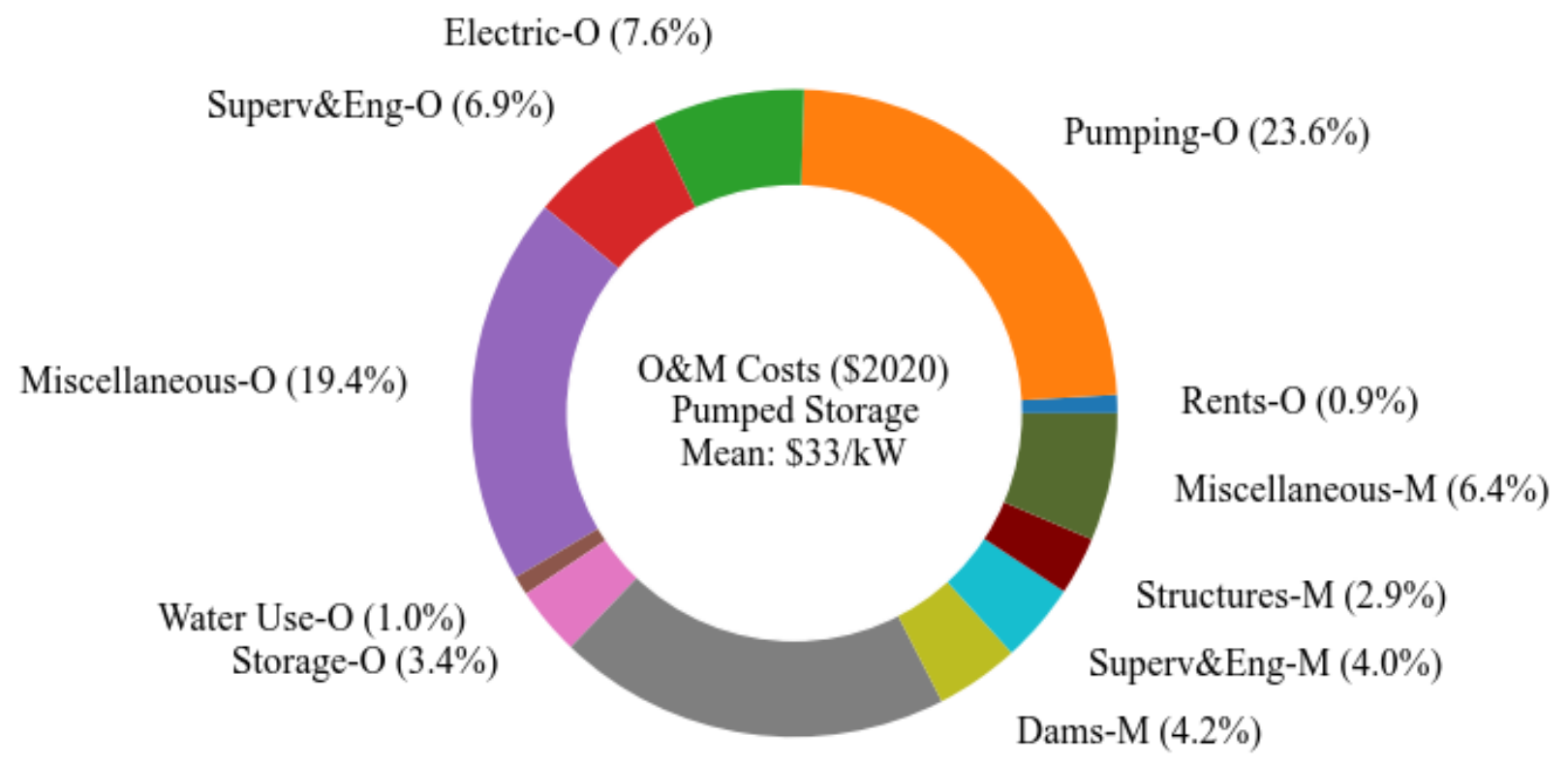

Electric-M (19.7\%)

Figure 25. O\&M cost account breakdown for PSH plants. 


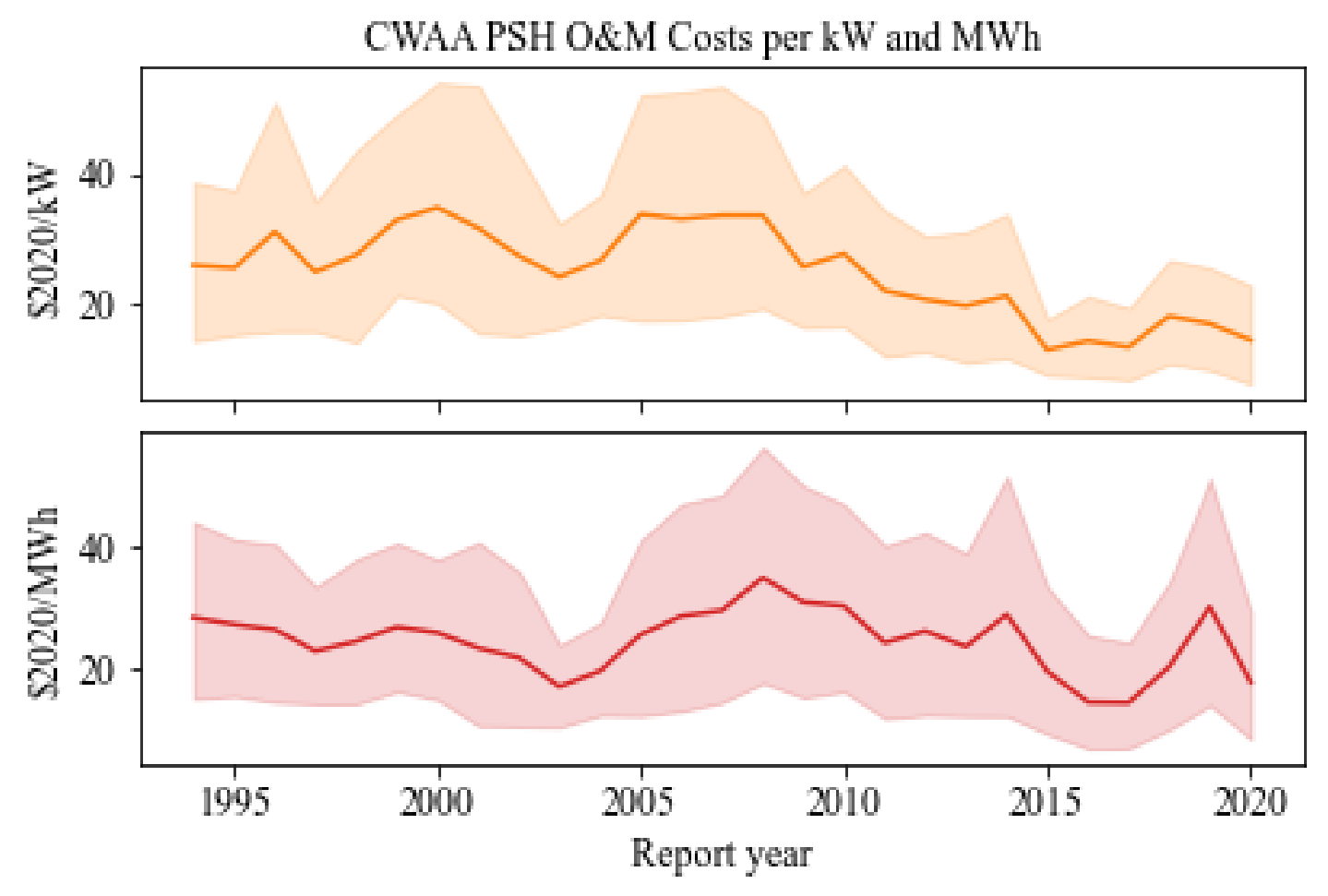

Figure 26. Time series of annual average O\&M costs for PSH plants in terms of cost per kilowatt and cost per megawatt-hour. Shaded region represents the $95 \%$ confidence interval.

\section{CONCLUSIONS AND FUTURE WORK}

Toward the aim of assessing the potential of Form 1 as a hydropower cost database, this report describes how the Form 1 data was compiled and provides visualizations, as well as brief discussions, of the data. This process revealed several potential advantages, as well as some challenges, of the Form 1 data for hydropower industry uses.

A key advantage of the Form 1 data is the breakdown of capital and O\&M costs by components. This type of cost breakdown for active plants is not available in any other public database, representing a unique advantage of the Form 1 data. In addition, the O\&M data is provided separately by component on an annual basis and could provide important insights into related hydropower trends. Previous cost modeling efforts for the BCM [3] used total aggregate capital and operating cost data. Research combining the Form 1 database with other relevant databases would enable more detailed analyses of hydropower O\&M costs that relate the data to important cost drivers.

The key challenge with using the Form 1 data is related to the nature of the capital costs. First, the Form 1 capital costs are book costs, which track the rolling cash cost of current plant assets. Since book costs are not adjusted to the dollar year of the respective report and the date of asset purchases are not recorded, the value of assets purchased before 1994 are based on an unknown dollar year and cannot be properly adjusted for inflation. So, although the capital cost information is a useful representation of the dollars invested into a given plant over time, the data will likely underestimate costs if used in applied cost modeling efforts. Second, most of the Form 1 data is for much older plants, so the capital cost estimates might not represent the cost of new hydropower projects even if they could be properly adjusted for 
inflation. This second challenge is related to the submission requirement for the Form 1 data, which is restricted to major utilities as previously defined and excludes small utilities, federal agencies, or other facilities not regulated by FERC. This resulted in an underrepresentation of small projects in the Form 1 data relative to the national hydropower fleet. In addition, since there are only a few potential large-scale US hydropower projects remaining, new projects will tend to be excluded from the Form 1 data unless part of a reporting major utility. Still, the Form 1 data includes a wide range of capacities and dam types that represent about $22 \%$ of active US hydropower capacity and $61 \%$ of pumped storage capacity, which will be useful for understanding the features and required innovations for future hydropower projects.

The other key challenge to using the Form 1 data is that it requires technical expertise with FoxPro databases, limiting its accessibility to many stakeholders. In addition, the user data in the Form 1 database requires significant manual processing, such as naming differences across years and coordinating entries for shared plant assets among owners. This report helps to address some of these issues by producing a database of the Form 1 data that is publicly available in Excel/CSV format with identifiers linking the data to other hydropower-related databases such as NID and EHA. In addition, standardized naming conventions for plants and other standards, where applicable, would further support the accessibility of the Form 1 data to hydropower stakeholders.

Overall, despite some challenges, the Form 1 data represents a unique publicly available database on hydropower asset costs that, in combination with other hydropower data sets, would support a better understanding of industry trends and enable a variety of cost modeling opportunities when combined with other sources of data. Potential applications of the Form 1 database include classification analyses, empirical cost modeling, assessments of improved cost reporting standards, sensitivity or tradeoff analysis for plant designs, and assessments of innovation options. 


\section{REFERENCES}

[1] Oladosu, G. A., J. Werble, W. Tingen, A. Witt, M. Mobley, and P. O’Connor. 2021. "Costs of mitigating the environmental impacts of hydropower projects in the United States." Renew Sustain Energy Rev 135: 110121. https://doi.org/10.1016/j.rser.2020.110121.

[2] O'Connor, P. W., Q. Fen, K. Zhang, and S. T. Deneale. 2015. Hydropower Baseline Cost Modeling.

[3] O’Connor, P. W., S. T. DeNeale, D. R. Chalise, E. Centurion, and A. Maloof. 2015. Hydropower Baseline Cost Modeling, Version 2.

[4] US Army Corps of Engineers. 2021. "National Inventory of Dams." https://nid.usace.army.mil/\#/.

[5] Johnson, M. M., S-C. Kao, N. M. Samu, and R. Uria-Martinez. 2021. "Existing Hydropower Assets." doi:10.21951/EHA_FY2021/1782791.

[6] "Uniform system of accounts prescribed for public utilities and licensees subject to the provisions of the Federal Power Act." 2020. Code of Federal Regulations, Order 218, 25 FR 5014, June 7, 1960.

[7] Federal Energy Regulatory Commission. 2021. Form 1, "Electric Utility Annual Report." https://www.ferc.gov/industries-data/electric/general-information/electric-industry-forms/form-1electric-utility-annual (accessed September 23, 2021).

[8] Singh, D. HydroSource. Oak Ridge National Laboratory. https://hydrosource.ornl.gov/ (accessed September 23, 2021).

[9] Bureau of Reclamation. 2021. "Construction Cost Trends." https://www.usbr.gov/tsc/techreferences/mands/cct.html (accessed September 23, 2021).

[10] Samu, N. M., D. Singh, M. Johnson, S-C. Kao, S. Gangrade, S. Curd, et al. 2020. "The 2020 National Hydropower Map." doi:10.21951/NationalHydropowerMap_FY20/163. 


\section{APPENDIX A. EQUATIONS IN THE BCM (Version 2)}

This section includes additional information about the Form 1 data that is not essential to the data review.

Table A.1 shows the empirical cost equations generated by the baseline cost model effort [3].

Table A.1. Empirical equations for initial cost of capital (ICC) and operation and maintenance (O\&M) costs by resource category from the baseline cost model, Version 2 [3]

\begin{tabular}{ll}
\hline \multicolumn{1}{c}{ Project type } & \multicolumn{1}{c}{$\begin{array}{c}\text { Cost model equation } \\
\text { (ICC; O\&M in 2014\$; P in MW; H in ft) }\end{array}$} \\
\hline Non-powered dams & ICC $=11,489,245 P^{0.976} H^{-0.240}$ \\
New stream-reach development & ICC $=9,605,710 P^{0.977} H^{-0.126}$ \\
Pumped storage hydropower & ICC (retrofit) $=3,008,246 P e^{-0.000460 P}$ \\
Canal/conduit & ICC (greenfield $)=4,882,655 P e^{-0.000776 P}$ \\
Unit addition to plant & ICC $=9,297,820, P^{0.810} H^{-0.102}$ \\
Unit generator rewind & ICC $=4,163,746 P^{0.741}$ \\
\hline
\end{tabular}




\section{APPENDIX B. FORM 1 COST DATA DESCRIPTIONS}

This appendix provides tables describing the capital and operating cost accounts. These tables cite text from the "Uniform System of Accounts" in the Code of Federal Regulations [6] and the Form 1 submission document [7]. These sources should be referenced for full descriptions of these accounts. Each cost account applies to the items described in these tables and the relevant cost components related to the conservation of fish, wildlife, and recreation. For example, the land account will "include the cost of land and land rights used in connection with (1) the conservation of fish and wildlife, and (2) recreation."

Table B.1. Descriptions of the capital cost accounts for hydropower and pumped storage plants as reported in the Code of Federal Regulations [6] and the Form 1 submission document [7]

\begin{tabular}{ll}
\hline \multicolumn{1}{c}{ Value } & \multicolumn{1}{c}{ Description } \\
\hline $\begin{array}{l}\text { Land and land rights } \\
\text { Account } 330 \\
\text { (cost_land) }\end{array}$ & $\begin{array}{l}\text { "This account shall include the cost of land and land rights used in connection with } \\
\text { hydraulic power generation." }\end{array}$ \\
\hline $\begin{array}{l}\text { Structures and } \\
\text { improvements }\end{array}$ & "This account shall include the cost in place of structures and improvements used in \\
Account 331 & connection with hydraulic power generation. For Major utilities, it shall also include \\
(cost_structures) & the cost of land and land rights used in connection with (1) the conservation of fish \\
\hline
\end{tabular}

Reservoirs, dams, and

"This account shall include the cost in place of facilities used for impounding, waterways. Account 332 (cost_facilities) collecting, storage, diversion, regulation, and delivery of water used primarily for generating electricity. For Major utilities, it shall also include the cost in place of structures and improvements used in connection with (1) the conservation of fish and wildlife, and (2) recreation."

"ITEMS

1. Bridges and culverts (when not a part of roads or railroads).

2. Clearing and preparing land.

3. Dams, including wasteways, spillways, flash boards, spillway gates with operating and control mechanisms, tunnels, gate houses, and fish ladders.

4. Dikes and embankments.

5. Electric system, including conductors control system, transformers, lighting fixtures, etc.

6. Excavation, including shoring, bracing, bridging, refill, and disposal of excess excavated material.

7. Foundations and settings specially constructed for and not expected to outlast the apparatus for which provided.

8. Intakes, including trash racks, rack cleaners, control gates and valves with operating mechanisms, and intake house when not a part of station structure. 9. Platforms, railings, steps, gratings, etc., appurtenant to structures listed herein. 10. Power line wholly identified with items included herein.

11. Retaining walls.

12. Water conductors and accessories, including canals, tunnels, flumes, penstocks pipe conductors, forebays, tailraces, navigation locks and operating mechanisms, waterhammer and surge tanks, and supporting trestles and structures. 13. Water storage reservoirs, including dams, flashboards, spillway gates and operating mechanisms, inlet and outlet tunnels, regulating valves and valve towers, silt and mud sluicing tunnels with valve or gate towers, and all other structures wholly identified with any of the foregoing items." 
Table B.1. Descriptions of the capital cost accounts for hydropower and pumped storage plants as reported in the Code of Federal Regulations [6] and the Form 1 submission document [7] (continued)

\begin{tabular}{|c|c|}
\hline Value & Description \\
\hline $\begin{array}{l}\text { Water wheels, turbines and } \\
\text { generators } \\
\text { Account } 333 \\
\text { (PSH: cost_wheels, Hydro: } \\
\text { cost_equipment) }\end{array}$ & $\begin{array}{l}\text { "This account shall include the cost installed of water wheels and hydraulic turbines } \\
\text { (from connection with penstock or flume to tailrace) and generators driven thereby } \\
\text { devoted to the production of electricity by water power or for the production of power } \\
\text { for industrial or other purposes, if the equipment used for such purposes is a part of } \\
\text { the hydraulic power plant works." } \\
\text { "ITEMS } \\
\text { 1. Exciter water wheels and turbines, including runners, gates, governors, pressure } \\
\text { regulators, oil pumps, operating mechanisms, scroll cases, draft tubes, and draftube } \\
\text { supports. } \\
\text { 2. Fire-extinguishing equipment. } \\
\text { 3. Foundations and settings, specially constructed for and not expected to outlast the } \\
\text { apparatus for which provided. } \\
\text { 4. Generator cooling system, including air cooling and washing apparatus, air fans } \\
\text { and accessories, air ducts, etc. } \\
\text { 5. Generators-main, a.c. or d.c., including field rheostats and connections for self- } \\
\text { excited units and excitation system when identified with the generating unit. } \\
\text { 6. Lighting systems. } \\
\text { 7. Lubricating systems, including gauges, filters, tanks, pumps, piping, etc. } \\
\text { 8. Main penstock valves and appurtenances, including main valves, control } \\
\text { equipment, bypass valves and fittings, and other accessories. } \\
\text { 9. Main turbines and water wheels, including runners, gates, governors, pressure } \\
\text { regulators, oil pumps, operating mechanisms, scroll cases, draft tubes, and draft-tube } \\
\text { supports. } \\
\text { 10. Mechanical meters and recording instruments. } \\
\text { 11. Miscellaneous water-wheel equipment, including gauges, thermometers, meters, } \\
\text { and other instruments. } \\
\text { 12. Platforms, railings, steps, gratings, etc., appurtenant to apparatus listed herein. } \\
\text { valves, fittings and insulations, piers and anchorage, and excavation and backfill." }\end{array}$ \\
\hline $\begin{array}{l}\text { Accessory electric } \\
\text { equipment } \\
\text { Account } 334 \\
\text { (PSH: cost_electric, Hydro: } \\
\text { cost_equipment) }\end{array}$ & $\begin{array}{l}\text { "This account shall include the cost installed of auxiliary generating apparatus, } \\
\text { conversion equipment, and equipment used primarily in connection with the control } \\
\text { and switching of electric energy produced by hydraulic power and the protection of } \\
\text { electric circuits and equipment, except electric motors used to drive equipment } \\
\text { included in other accounts, such motors being included in the account in which the } \\
\text { equipment with which they are associated is included." } \\
\text { "ITEMS } \\
\text { 1. Auxiliary generators, including boards, compartments, switching equipment, } \\
\text { control equipment, and connections to auxiliary power bus. } \\
\text { 2. Excitation system, including motor, turbine, and dual-drive exciter sets and } \\
\text { rheostats, storage batteries and charging equipment, circuit breakers, panels and } \\
\text { accessories, knife switches and accessories, surge arresters, instrument shunts, } \\
\text { conductors and conduit, special supports for conduit, generator field and exciter } \\
\text { switch panels, exciter bus tie panels, generator and exciter rheostats, etc., special } \\
\text { housings, protective screens, etc. } \\
\text { 3. Generator main connections, including oil circuit breakers and accessories, } \\
\text { disconnecting switches and accessories, operating mechanisms and interlocks, } \\
\text { current transformers, potential transformers, protective relays, isolated panels and } \\
\text { equipment, conductors and conduit, special supports for generator main leads, } \\
\text { grounding switch, etc., special housings, protective screens, etc. } \\
\text { 4. Station buses, including main, auxiliary, transfer, synchronizing, and fault ground } \\
\text { buses, including oil circuit breakers and accessories, disconnecting switches and }\end{array}$ \\
\hline
\end{tabular}


Table B.1. Descriptions of the capital cost accounts for hydropower and pumped storage plants as reported in the Code of Federal Regulations [6] and the Form 1 submission document [7] (continued)

\begin{tabular}{l} 
Value Description \\
\hline accessories, operating mechanisms and interlocks, reactors and accessories, voltage \\
regulators and accessories, compensators, resistors starting transformers, current \\
transformers, potential transformers, protective relays, storage batteries, and \\
charging equipment, isolated panels and equipment, conductors and conduit, special \\
supports, special fire-extinguishing system, and test equipment. \\
5. Station control system, including station switchboards with panel wiring panels \\
with instruments and control equipment only, panels with switching equipment \\
mounted or mechanically connected, trucktype boards complete, cubicles, station \\
supervisory control devices, frequency control equipment, master clocks, watt-hour \\
meter, station totalizing watt-meter, storage batteries, panels and charging sets, \\
instrument transformers for supervisory metering, conductors and conduit, special \\
supports for conduit, switchboards, batteries, special housings for batteries, \\
protective screens, doors, etc."
\end{tabular}

Miscellaneous power plant equipment

Account 335

(PSH:

cost_misc_equipment, Hydro: cost_equipment)
"This account shall include the cost installed of miscellaneous equipment in and about the hydroelectric generating plant which is devoted to general station use and is not properly includible in other hydraulic production accounts." "ITEMS

1. Compressed air and vacuum cleaning systems, including tanks, compressors, exhausters, air filters, piping, etc.

2. Cranes and hoisting equipment, including cranes, cars, crane rails, monorails, hoists, etc., with electric and mechanical connections.

3. Fire-extinguishing equipment for general station use.

4. Foundations and settings, specially constructed for and not expected to outlast the apparatus for which provided.

5. Locomotive cranes not includible elsewhere.

6. Locomotives not includible elsewhere.

7. Marine equipment, including boats, barges, etc.

8. Miscellaneous belts, pulleys, countershafts, etc.

9. Miscellaneous equipment, including atmospheric and weather indicating devices, intrasite communication equipment, laboratory equipment, insect control equipment, signal systems, callophones, emergency whistles and sirens, fire alarms, and other similar equipment.

10. Railway cars, not includible elsewhere.

11. Refrigerating system, including compressors, pumps, cooling coils, etc. 12. Station maintenance equipment, including lathes, shapers, planers, drill presses, hydraulic presses, grinders, etc., with motors, shafting, hangers, pulleys, etc. 13. Ventilating equipment, including items wholly identified with apparatus listed herein."

Roads, railroads and bridges

Account 336

(cost_roads)
"This account shall include the cost of roads, railroads, trails, bridges, and trestles used primarily as production facilities. It includes also those roads, etc., necessary to connect the plant with highway transportation systems, except when such roads are dedicated to public use and maintained by public authorities."

" ITEMS

1. Bridges, including foundations, piers, girders, trusses, flooring, etc.

2. Clearing land.

3. Railroads, including grading, ballast, ties, rails, culverts, hoists, etc.

4. Roads, including grading, surfacing, culverts, etc.

5. Structures, constructed and maintained in connection with items listed herein.

6. Trails, including grading, surfacing, culverts, etc.

7. Trestles, including foundations, piers, girders, trusses, flooring, etc. 
Table B.1. Descriptions of the capital cost accounts for hydropower and pumped storage plants as reported in the Code of Federal Regulations [6] and the Form 1 submission document [7] (continued)

\begin{tabular}{ll}
\hline \multicolumn{1}{c}{ Value } & \multicolumn{1}{c}{ Description } \\
\hline Asset retirement costs for & "This account shall include asset retirement costs on plant included in the hydraulic \\
hydraulic production plant. & production function." \\
Account 337 & \\
(asset_retire_cost)
\end{tabular}

Table B.2. Descriptions of the operating expense accounts for hydropower and pumped storage plants as reported in the Code of Federal Regulations [6] and the Form 1 submission document [7]

\begin{tabular}{|c|c|}
\hline Value & Description \\
\hline $\begin{array}{l}\text { Operation supervision and } \\
\text { engineering } \\
\text { Account } 535 \\
\text { (expns_operations) }\end{array}$ & $\begin{array}{l}\text { "This account shall include the cost of labor and expenses incurred in the general } \\
\text { supervision and direction of the operation of hydraulic power generating stations. } \\
\text { Direct supervision of specific activities, such as hydraulic operation, generator } \\
\text { operation, etc., shall be charged to the appropriate account." } \\
\text { "ITEMS } \\
\text { Hydraulic Labor: } \\
\text { 1. Supervising hydraulic operation. } \\
\text { 2. Removing debris and ice from trash racks, reservoirs and waterways. } \\
\text { 3. Patrolling reservoirs and waterways. } \\
\text { 4. Operating intakes, spillways, sluiceways and outlet works. } \\
\text { 5. Operating bubbler, heater or other deicing systems. } \\
\text { 6. Ice and log jam work. } \\
\text { 7. Operating navigation facilities. } \\
\text { 8. Operations relating to conservation of game, fish, forests, etc. } \\
\text { 9. Insect control activities. } \\
\text { Electric Labor: } \\
\text { 10. Supervising electric production. } \\
\text { 11. Operating prime movers, generators and auxiliary equipment. } \\
\text { 12. Operating generator cooling system. } \\
\text { 13. Operating lubrication and oil control systems, including oil purification. } \\
\text { 14. Operating switchboards, switchgear and electric control and protection } \\
\text { equipment. } \\
\text { 15. Keeping plant log and records and preparing reports on plant operations. } \\
\text { 16. Testing, checking and adjusting meters, gauges, and other instruments, relays, } \\
\text { controls and other equipment in the plant. } \\
\text { 17. Cleaning plant equipment when not incidental to maintenance work. } \\
\text { 18. Repacking glands. Miscellaneous Labor: } \\
\text { 19. General clerical and stenographic work. } \\
\text { 21. Building service. } \\
\text { 22. Care of grounds, including snow removal, cutting grass, etc. } \\
\text { 24. Miscellaneous labor." }\end{array}$ \\
\hline $\begin{array}{l}\text { Water for power } \\
\text { Account } 536 \\
\text { (expns_water_pwr) }\end{array}$ & $\begin{array}{l}\text { "This account shall include the cost of water used for hydraulic power generation." } \\
\text { "ITEMS } \\
\text { 1. Cost of water purchased from others, including water tolls paid reservoir companies. } \\
\text { 2. Periodic payments for licenses or permits from any governmental agency for } \\
\text { water rights, or payments based on the use of the water. } \\
\text { 3. Periodic payments for riparian rights. } \\
\text { 4. Periodic payments for headwater benefits or for detriments to others. } \\
\text { 5. Cloud seeding." }\end{array}$ \\
\hline
\end{tabular}


Table B.2. Descriptions of the operating expense accounts for hydropower and pumped storage plants as reported in the Code of Federal Regulations [6] and the Form 1 submission document [7] (continued)

\begin{tabular}{|c|c|}
\hline Value & Description \\
\hline $\begin{array}{l}\text { Hydraulic expenses } \\
\text { Account } 537 \\
\text { (expns_hydraulic) }\end{array}$ & $\begin{array}{l}\text { "This account shall include the cost of labor, materials used and expenses incurred } \\
\text { in operating hydraulic works including reservoirs, dams, and waterways, and in } \\
\text { activities directly relating to the hydroelectric development outside the generating } \\
\text { station." } \\
\text { "ITEMS } \\
\text { Labor: } \\
\text { 1. Supervising hydraulic operation. } \\
\text { 2. Removing debris and ice from trash racks, reservoirs and waterways. } \\
\text { 3. Patrolling reservoirs and waterways. } \\
\text { 4. Operating intakes, spillways, sluiceways, and outlet works. } \\
\text { 5. Operating bubbler, heater or other deicing systems. } \\
\text { 6. Ice and log jam work. } \\
\text { 7. Operating navigation facilities. } \\
\text { 8. Operations relating to conservation of game, fish, forests, etc. } \\
\text { 9. Insect control activities. } \\
\text { Materials and Expenses: } \\
\text { 10. Insect control materials. } \\
\text { 11. Lubricants, packing, and other supplies used in operation of hydraulic } \\
\text { equipment. } \\
\text { 12. Transportation expenses" }\end{array}$ \\
\hline $\begin{array}{l}\text { Electric expenses } \\
\text { Account } 538 \text { (expns_electric) }\end{array}$ & $\begin{array}{l}\text { "This account shall include the cost of labor, materials used and expenses incurred } \\
\text { in operating prime movers, generators, and their auxiliary apparatus, switchgear, } \\
\text { and other electric equipment, to the point where electricity leaves for conversion for } \\
\text { transmission or distribution. " } \\
\text { "ITEMS } \\
\text { Labor: } \\
\text { 1. Supervising electric production. } \\
\text { 2. Operating prime movers, generators and auxiliary equipment. } \\
\text { 3. Operating generator cooling system. } \\
\text { 4. Operating lubrication and oil control systems, including oil purification. } \\
\text { 5. Operating switchboards, switchgear, and electric control and protection } \\
\text { equipment. } \\
\text { 6. Keeping plant log and records and preparing reports on plant operations. } \\
\text { 7. Testing, checking and adjusting meters, gauges, and other instruments, relays, } \\
\text { controls, and other equipment in the plant. } \\
\text { 8. Cleaning plant equipment when not incidental to maintenance work. } \\
\text { 9. Repacking glands. } \\
\text { Materials and Expenses: } \\
\text { 10. Lubricants and control system oils. } \\
\text { 11. Motor and generator brushes. }\end{array}$ \\
\hline $\begin{array}{l}\text { Miscellaneous hydraulic } \\
\text { power generation expenses } \\
\text { Account } 539 \\
\text { (PSH: expns_misc_power, } \\
\text { Hydro: } \\
\text { expns_generation) }\end{array}$ & $\begin{array}{l}\text { "This account shall include the cost of labor, materials used and expenses incurred } \\
\text { which are not specifically provided for or are not readily assignable to other } \\
\text { hydraulic generation operation expense accounts." } \\
\text { "ITEMS } \\
\text { "Labor: } \\
\text { 1. General clerical and stenographic work. } \\
\text { 2. Guarding and patrolling plant and yard. } \\
\text { 3. Building service. } \\
\text { 4. Care of grounds including snow removal, cutting grass, etc. } \\
\text { 5. Snow removal from roads and bridges. } \\
\text { 6. Miscellaneous labor. }\end{array}$ \\
\hline
\end{tabular}


Table B.2. Descriptions of the operating expense accounts for hydropower and pumped storage plants as reported in the Code of Federal Regulations [6] and the Form 1 submission document [7] (continued)

\begin{tabular}{|c|c|}
\hline Value & Description \\
\hline & $\begin{array}{l}\text { Materials and Expenses: } \\
\text { 7. General operating supplies, such as tools, gaskets, packing, waste, hose, } \\
\text { indicating lamps, record and report forms, etc. } \\
\text { 8. First-aid supplies and safety equipment. } \\
\text { 9. Employees' service facilities expenses. } \\
\text { 10. Building service supplies. } \\
\text { 11. Communication service. } \\
\text { 12. Office supplies, printing and stationery. } \\
\text { 13. Transportation expenses. } \\
\text { 14. Fuel. } \\
\text { 15. Meals, traveling and incidental expenses. } \\
\text { 16. Research, development, and demonstration expenses." }\end{array}$ \\
\hline $\begin{array}{l}\text { Rents } \\
\text { Account } 540 \\
\text { (expns_rents) }\end{array}$ & $\begin{array}{l}\text { "This account shall include all rents of property of others used, occupied or } \\
\text { operated in connection with hydraulic power generation, including amounts } \\
\text { payable to the United States for the occupancy of public lands and reservations for } \\
\text { reservoirs, dams, flumes, forebays, penstocks, power houses, etc., but not including } \\
\text { transmission right of way." } \\
\text { "ITEMS } \\
\text { 1. Insect control materials. } \\
\text { 2. Lubricants, packing, and other supplies used in operation of hydraulic } \\
\text { equipment. } \\
\text { 3. Supplies and expenses in conservation of game, fish, forests, etc. } \\
\text { 4. Transportation expense. } \\
\text { 5. Control system oils. } \\
\text { 6. Motor and generator brushes. } \\
\text { 7. General operating supplies, such as tools, gaskets, packing, waste hose, } \\
\text { indicating lamps, record and report forms, etc. } \\
\text { 8. First-aid supplies and safety equipment. } \\
\text { 9. Employees' service facilities expenses. } \\
\text { 10. Building service supplies. } \\
\text { 11. Communication service. } \\
\text { 12. Office supplies, printing and stationery. } \\
\text { 13. Transportation expenses. } \\
\text { 14. Fuel. } \\
\text { 15. Meals, traveling and incidental expenses.", }\end{array}$ \\
\hline
\end{tabular}

Maintenance supervision and "This account shall include the cost of labor and expenses incurred in the general engineering

Account 541

(expns_engnr) supervision and direction of the maintenance of hydraulic power generating stations. Direct field supervision of specific jobs shall be charged to the appropriate maintenance account."

Maintenance of structures Account 542 (expns_structures)

"This account shall include the cost of labor, materials used, and expenses incurred in maintenance of hydraulic structures, the book cost of which is includible in Account 331, Structures and Improvements... However, the cost of labor, materials used and expenses incurred in the maintenance of fish and wildlife, and recreation facilities, the book cost of which is includible in Account 331, Structures and Improvements, shall be charged to Account 545, Maintenance of Miscellaneous Hydraulic Plant."

Maintenance of reservoirs, "This account shall include the cost of labor, materials used, and expenses incurred dams, and waterways Account 543 in maintenance of plant includible in Account 332, Reservoirs, Dams, and (expns_dams) Waterways...However, the cost of labor materials used and expenses incurred in the maintenance of fish and wildlife, and recreation facilities, the book cost of 
Table B.2. Descriptions of the operating expense accounts for hydropower and pumped storage plants as reported in the Code of Federal Regulations [6] and the Form 1 submission document [7] (continued)

\begin{tabular}{|c|c|}
\hline Value & Description \\
\hline & $\begin{array}{l}\text { which is includible in Account 332, Reservoirs, Dams and Waterways, shall be } \\
\text { charged to Account 545, Maintenance of Miscellaneous Hydraulic Plant." }\end{array}$ \\
\hline $\begin{array}{l}\text { Maintenance of electric plant } \\
\text { Account } 544 \text { (expns_plant) }\end{array}$ & $\begin{array}{l}\text { "This account shall include the cost of labor, materials used and expenses incurred } \\
\text { in maintenance of plant includible in Account 333, Water Wheels, Turbines and } \\
\text { Generators, and account 334, Accessory Electric Equipment." }\end{array}$ \\
\hline $\begin{array}{l}\text { Maintenance of } \\
\text { miscellaneous hydraulic } \\
\text { plant } \\
\text { Account } 545 \\
\text { (expns_misc_plant) }\end{array}$ & $\begin{array}{l}\text { "This account shall include the cost of labor, materials used, and expenses incurred } \\
\text { in maintenance of plant, the book cost of which is includible in Account 335, } \\
\text { Miscellaneous Power Plant Equipment, and Account 336, Roads, Railroads and } \\
\text { Bridges." }\end{array}$ \\
\hline $\begin{array}{l}\text { Pumped storage expenses } \\
\text { (expns_pump_strg) }\end{array}$ & $\begin{array}{l}\text { This account is not described in the Code of Federal Regulations but is listed in the } \\
\text { Form } 1 \text { submission document under Line } 26 \text { of the Pumped Storage Generating } \\
\text { Plant Statistics (Large Plants) Schedule. }\end{array}$ \\
\hline $\begin{array}{l}\text { Pumping expenses } \\
\text { (pumping_expenses) }\end{array}$ & $\begin{array}{l}\text { This account is not described in the Code of Federal Regulations but is listed in the } \\
\text { Form } 1 \text { submission document under Line } 36 \text { of the Pumped Storage Generating } \\
\text { Plant Statistics (Large Plants) Schedule, along with the following note: "The cost of } \\
\text { energy used in pumping into the storage reservoir." }\end{array}$ \\
\hline
\end{tabular}

